Portland State University

PDXScholar

$12-2-2005$

\title{
Self-help Support Groups: Choices in Participation Among Women Facing Systemic Lupus Erythematosus (SLE)
}

Maria A. Pfeifer

Portland State University

Follow this and additional works at: https://pdxscholar.library.pdx.edu/open_access_etds

Part of the Health Policy Commons, Public Policy Commons, and the Urban Studies Commons Let us know how access to this document benefits you.

Recommended Citation

Pfeifer, Maria A., "Self-help Support Groups: Choices in Participation Among Women Facing Systemic Lupus Erythematosus (SLE)" (2005). Dissertations and Theses. Paper 4793.

https://doi.org/10.15760/etd.6685

This Thesis is brought to you for free and open access. It has been accepted for inclusion in Dissertations and Theses by an authorized administrator of PDXScholar. Please contact us if we can make this document more accessible: pdxscholar@pdx.edu. 


\section{THESIS APPROVAL}

The abstract and thesis of Maria A. Pfeifer for the Master of Urban Studies were presented December 2, 2005, and accepted by the thesis committee and the department.

COMMITTEE APPROVALS:

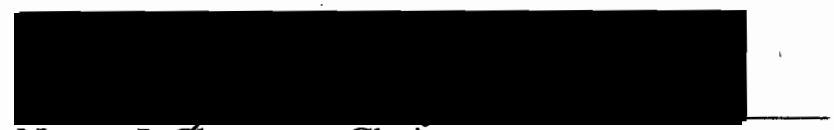

Nancy J. Chapman, Chair
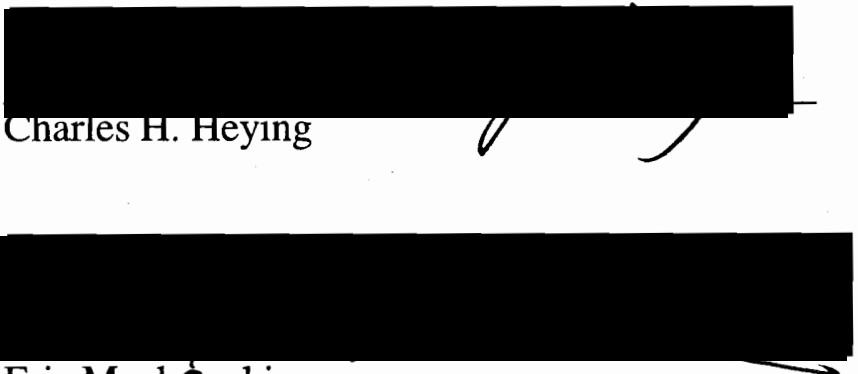

Eric Mankojwski

Representatye of the Office of Graduate Studies

DEPARTMENT APPROVAL:

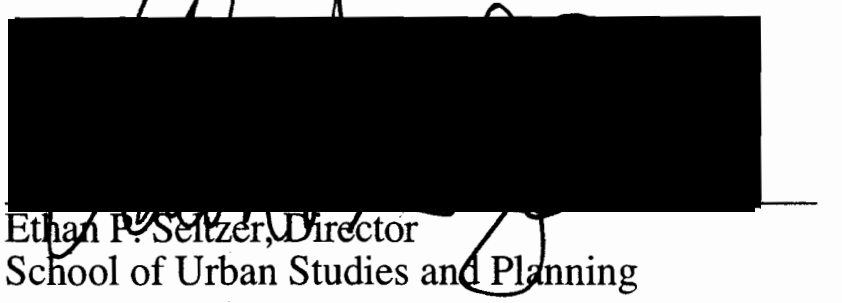




\begin{abstract}
An abstract of the thesis of Maria A. Pfeifer for the Master of Urban Studies presented December 2, 2005.
\end{abstract}

Title: Self-Help Support Groups: Choices in Participation Among Women Facing Systemic Lupus Erythematosus (SLE)

This research study explored the experiences of 19 women who had been diagnosed with, or were still seeking the diagnosis of SLE (lupus) and their decisions regarding support group participation. The aim of this study was to evaluate the variety of factors influencing their choices in types and sources of support, their coping strategies and the reasons behind their decisions to either choose or not choose lupus support groups as a viable support resource. Those women identified as support groups attendees recalled a more emotion-focused response to their diagnosis and showed stronger reliance on seeking emotional forms of support. Conversely, those women who chose not to participate in groups (non-attendees) utilized more problem-focused strategies when they received their news of the illness and indicated more reliance on instrumental forms of support. Additionally, the women who do not attend support groups did not seem to have more social support from outside sources, but did show a tendency to utilize relationship-focused coping more than other forms of coping strategies overall. Both groups showed a heavy reliance on their medical 
providers for both emotional and instrumental forms of support suggesting this source as an important factor in individual choices in coping strategies and support sources. The decisions to attend or not attend differed only in the strategies they relied on and specific group structure, timing and locations. The results of this study supports earlier research in the types and sources of social support used in adapting to a chronic illness. This study also encourages incorporating individual support services through medical providers and the development of programs that acknowledge individual coping and support needs. 


\section{SELF-HELP SUPPORT GROUPS:}

CHOICES IN PARTICIPATION AMONG WOMEN FACING

SYSTEMIC LUPUS ERYTHEMATOSUS (SLE)

by

MARIA A. PFEIFER

A thesis submitted in partial fulfillment of the requirements for the degree of

MASTER OF URBAN STUDIES

Portland State University

2006 


\section{Dedication}

I dedicate this project to the following individuals who were instrumental in providing the support and encouragement I needed:

$\sim$ to my mother, who has always been there

$\sim$ to my daughters Chelsea and Emily, for their loving spirits

$\sim$ to Dr. Michael Walczyk, for his medical guidance in keeping me here long enough to complete it

$\sim$ to all of my friends who believed in me

and, most importantly,

$\sim$ I give this labor of life to the women with whom I share in this journey, understanding that, just by living, we are heard. 
Acknowledgements

With immense appreciation to the following contributors of this project:

The Northwest Health Foundation in Portland, Oregon, for their grant that made this possible

Dr. Nancy Chapman, Portland State University,

for her professional guidance, inspiration to keep trying and for being a true role model

Denise Ramsden, for her transcription expertise

The lupus support group facilitators, for their support in the mission of this study

and

the women who shared their lives with the belief that this project would matter;

you always do 


\section{TABLE OF CONTENTS}

Acknowledgements..................................................................... ii

List of Tables....................................................................................

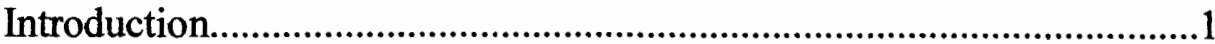

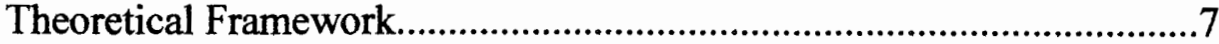

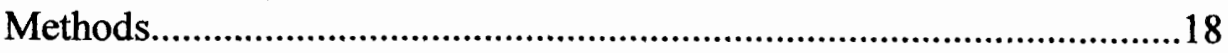

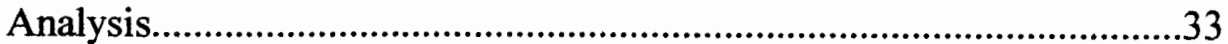

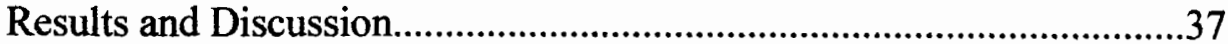

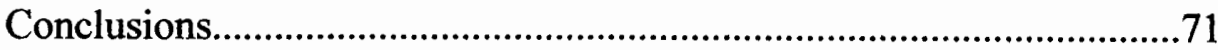

Terminal References............................................................ 78

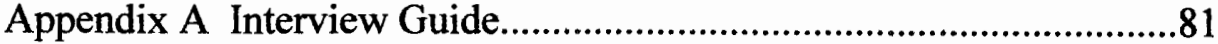

Appendix B Northwest Health Foundation Grant Confirmation

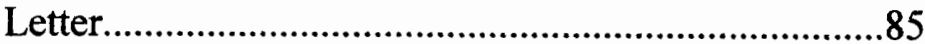




\section{LIST OF TABLES}

Table 1: Age Range of Study Participants.

Table 2: Demographic Information of Study Sets.................................26

Table 3: Major Codes Used in Data Analysis............................................35

Table 4: Experiences Prior To and Following Diagnosis of

Lupus. 39

Table 5: Coping Strategy Definitions. 44

Table 6: Coping Responses at Time of Diagnosis. 45

Table 7: Coping Responses Mentioned During Entire Interview

Table 8: Relationship-focused Coping Responses. .53

Table 9: Types of Social Support. .58

Table 10: Sources of Social Support. .63

Table 11: Top Reasons for Not Attending .66 
Introduction

Systemic Lupus Erythematosus (SLE), otherwise known as lupus, is one of many autoimmune diseases in which the body responds to a perceived threat to itself by developing aggressive cell activity. Although this activity is a normal function of the immune system, in autoimmune diseases, the "immune surveillance system" (Wallace, 2000) accelerates to the point that it attacks the body's own healthy tissue. According to the Lupus Foundation of America website (2005), ninety percent of those diagnosed with lupus are women between the ages of 15-45 years of age. The prevalence of this disease is conservatively estimated to affect over 1.5 million women, men and children in this country (LFA, 2005). The S.L.E. Foundation website (2005) estimates lupus to be more prevalent than "cerebral palsy, multiple sclerosis, sickle-cell anemia and cystic fibrosis combined..." A report released by the Centers for Disease Control (Medical College of Wisconsin website, 2005) stated that the number of lupus deaths increased between years 1979 to 1998 by 527 reported diagnoses. It also notes that the death rates for African-American women with lupus rose $70 \%$ within this same 20 -year period. This is consistent with previous research which suggests that lupus occurs more often among minority women (in particular Asian, Hispanic and Native American women). The report does not clarify whether this increase is due to more occurrences of lupus or simply that medical providers have improved their familiarity with lupus in general. 
Receiving a diagnosis of lupus can be difficult due to the variability and inconsistency of the symptoms, test results and the similarities to other chronic conditions that sometimes mask the presence of lupus activity. The general symptoms of lupus include low-grade fevers, photosensitivity, muscle weakness, joint pain, skin rashes and fatigue. If left untreated, or dismissed by patients or medical providers, the disease may progress to a more serious level leading to organ involvement and potentially fatal consequences. Lupus symptoms are practically 'invisible' and the suffering many women go through is often minimized by others calling them 'lazy' or 'whiners' simply because they do not see any disfigurement with which to sympathize. There is no known cure for lupus, which leaves many individuals with the reality of a chronic condition requiring constant health monitoring, adaptation and adjustment. Lupus is no longer considered a 'death-sentence' within the medical communities, as there are more medications available and an increased awareness of lupus assisting medical providers in giving patients earlier diagnoses and better treatment options. Generally, those who do not have lupus do not recognize how disabling this condition can be. As with other chronic illnesses, lupus forces individuals to face many losses involving self-identity, physical capabilities and challenging them in their ability to live independently. In some cases, individuals experience increased social isolation due to the physical restrictions caused by lupus.

In order to cope, many individuals rely on a variety of different 
supportive resources. Research in social support and coping strategies solidly points to strengthening support as a means of improving illness adjustment (Cohen \& Wills, 1985; Lyons, et al., 1995; Hurdle, 2001; Littrell, 1996). One avenue for improving or strengthening an individual's social support is participation in an illness-related support group. There are many types of support groups ranging from treatment groups led by professionals to informal groups such as self-help or peer-led support groups commonly offered through organizations, churches and medical outreach programs. Participation in groups is encouraged by the helping professions as a means of providing the individuals opportunities to improve coping skills and to receive both emotional and instrumental forms of support.

The individual's expectations of a group experience, however, may not be met if the type of support they seek is not available. There are differences in the coping strategies women use, in the experiences they have, and in their support needs. It is especially important that medical and service providers know these differences, because they first work with women at the time of the diagnosis and are instrumental at the beginning of their adaptation process. It is, therefore, imperative to develop an assessment of some crucial factors regarding an individual's needs, expectations, and the resources available before any blanket recommendation of group participation is made.

I received my own diagnosis in 1998 after approximately three years of questionable health. I was very independent and knew that facing new health 
challenges would be very difficult for me, especially as a single-mother. I declined when my own doctor recommended participation in a local lupus support group. I preferred dealing with problems, even this new illness, on my own. Based on what I knew of support groups through undergraduate studies in psychology and working in the social work field, I viewed groups as important in providing emotional support and to provide a forum for individuals for emotional disclosure. Unfortunately, another source for my perspective on groups was likely based on the media, primarily comedies that portrayed groups as "whining sessions". My eventual decision to attend a support group was to seek information about lupus, to begin my own process of adjusting to lupus and to find out if my assumptions about groups were correct.

In speaking with a number of women for over the past seven years, I have learned that coping with lupus is a daily, complicated, and multi-faceted process. It is a very personal illness that must be faced on an individual level every day with the acceptance that you are literally your own worst enemy. One has to wonder about the emotional toll lupus takes on an individual's sense of being as they realize that it is their own body betraying them. It isn't an illness that involves a menacing invasion or disfigurement that can be seen and sympathized with by others. Lupus requires a person to evaluate how they handle the stressors of life and to learn how to meet challenges without accelerating their body's defense responses which could cause them further physical harm. 
Participation in groups is encouraged by the helping professions as a means of providing the individuals opportunities to improve coping skills and to receive both emotional and instrumental forms of support. The individual's expectations of a group experience, however, may not be met if the type of support they seek is not available. There are differences in the coping strategies women use, in the experiences they have, and in their support needs. It is especially important that medical and service providers know these differences, because they first work with women at the time of the diagnosis and are instrumental at the beginning of their adaptation process. It is, therefore, imperative to develop an assessment of some crucial factors regarding an individual's needs, expectations, and the resources available before any blanket recommendation of group participation is made.

There is little research that explores these support needs among women diagnosed with lupus and, more specifically, the motivating influences behind support group participation. Although there has been some research that explores the social support and coping patterns of individuals with other autoimmune diseases such as rheumatoid arthritis, fibromyalgia and MS, there is limited information and understanding of what peer-facilitated or self-help support groups offer women with lupus. This study stems from my involvement with four different self-help lupus support groups in the greater Portland area where I noticed that the number of women who attended the group meetings were far fewer than how many women were actually registered as members of 
these groups. I wondered where the other women were and whether they weren't attending these groups for the same reasons that I initially had. From this experience, the purpose of this project was to open up dialogue between these women and the community in order to begin shedding some light on their lives with lupus. I believed that despite their 'invisibility' medically or due to the social isolation as a result of physical limitations, an opportunity had to be provided so that their voices can be heard.

Therefore, the questions asked during this study were focused on learning more about the early stages of illness adaptation beginning with their diagnosis, the types of and sources of social support they seek in managing their health, the perceptions that women have of support groups. The specific research question guiding this project was: What are the main reasons that lead some women to attend a lupus support group and lead others to choose not to attend? 


\section{Theoretical Framework}

The issues facing individuals who have chronic illnesses are not limited to the physical and emotional challenges, but also include other challenges of meeting daily needs (e.g., employment and finance, living skills, social interaction, self-identity). It is in the coping strategies where the chosen support choices are put to work. In a study by Komproe, et al. (1997, p. 74), it is determined that "emotional support or information received from others can be helpful only as long as they influence the patient's coping process..." In terms of adaptation, the appropriate tools are key in being able to fully utilize the types of support received from a strong network of matched sources available.

\section{Coping Strategies and Adaptation to Lupus}

When facing traumatic events or life changes, research shows that there are many elements to consider when studying the process of coping. For this study, coping was defined as a process in which an individual appraises a situation or condition and responds with behavior that is believed to reduce the effects of a stressor (Littrell, 1996). The choice of a coping strategy has been linked to determining the effectiveness of adjustment to disease (Aikens, et al., 1997; Littrell, 1996; Pakenham, 1999; Revenson \& Felton, 1989; Newman, 1990; Schwartz, 1999). A majority of researchers refer to two main types of coping strategies: emotion-focused or problem-focused. Emotion-focused coping strategies involve attempts to alter the emotional response to a stressor, 
condition or situation. Even denial, an emotion-focused strategy which individuals use to distance themselves from the illness, is seen as beneficial psychologically (Littrell, 1996), but using this coping strategy for a long duration may be detrimental to one's overall health.

Problem-focused strategies target the source of stress. This strategy utilizes skills, information and techniques to alter the source of stress. These strategies have been associated with being used by individuals with a strong perceived sense of control over life and high self-esteem, both of which have been observed to also buffer stress (Thoits, 1995). Charmaz (1983) studied the losses associated with illness and refers to the loss of sensing personal control among individuals with chronic illness as a significant stressor they face in their adaptation. However, research is inconsistent and some studies have shown problem-focused to not have any influence on mental health and only confirms the need to more research to understand the complexities in the relationships between strategies and outcomes.

A third strategy to consider in illness adaptation is that of relationshipfocused coping (Lyons, et al., 1995). This strategy places greater attention on the relational factors in the coping and illness-adaptation process. Whereas the emotional- and problem-focused strategies are individualistic in their approaches, the relationship-focused strategy targets the individual's social network as a vital source of support, guidance and service that is often necessary in coping with a chronic illness. This strategy acknowledges that the individual 
facing the illness also considers the effects their illness has on others and strives to manage their health challenges in order to provide their family and friends a sense of "well-being". Relationship-focused coping has not been specifically studied within a lupus sample, yet there has been some study of relationships such as of couples dealing with lupus and their levels of emotional intimacy (Druley, et al., 1997).

In a study by Folkman \& Lazarus (1980, p. 218), not only do they indicate that an individuals' styles of coping generally involve both emotionand problem-focused strategies overall, but “...[that] people are more variable than consistent in their coping patterns". Pakenham (1999) also suggests coping to resemble more of a spectrum than two distinct groups of behaviors as they applied to adjustment to MS, an autoimmune disease that often considered the health problem before testing for lupus occurs. Therefore, in order for coping and social support interventions to provide beneficial assistance to women with lupus, there must be a match between the individual and the resource that meets their expectations or perceptions in order to benefit from support (Jacobson, 1986; Rook, 1984).

Support: What does it mean?

Thoits (1995, p.64) refers to support as "a social 'fund' from which people may draw when handling stressors". Recent research suggests that the quality, rather than the quantity, of social support can determine health 
outcomes (Franks, et al., 2004). The sources and types of social support individuals rely on in their adaptation to illness are just as variable as the nature of lupus itself. There are various forms or types of support that have been used in previous research identifying them into the general categories of emotional or instrumental forms. The emotional forms or types of support are usually those forms that are used to address the emotional responses or needs to the stressor, which in this case is lupus. Examples of emotional forms include seeking understanding or feelings of comfort and belongingness. In a study by Sandstrom (1996), peer group participation among men diagnosed with HIV/AIDS was explored. The results show that those men who participated in the group were more likely to seek emotional forms of support than the men who did not attend. The men who did not attend sought more instrumental forms and did not see themselves as needing the group for support. Instrumental forms of support are associated with tools or skills that can be utilized to directly address the stressor or illness. These forms include such things as knowledge, information and forms like services or goods, sometimes referred to as 'materials' (Jacobson, 1986).

There is the need for flexibility in seeking various forms of support, as no one form works for every situation that an individual faces in their adapting to lupus. Just as one size does not fit all, successful living with a chronic, variable illness requires a variety of available resources. Knowing the type of support needed is something individuals must determine, or be assisted in 
determining, for themselves. Once they have decided on what they need, their next step is in finding the appropriate source for support.

There are some common sources used by individuals that are frequently studied in social support research. In addition to professional sources including counselors and medical providers, there are also non-professional sources such as family, friends, co-workers/employers, membership organizations, and the media that have been studied to determine their influence in the adaptation process for chronic conditions (Dunkel-Schetter, 1984; Hafen, et al., 1992; Pakenham, 1999; Sandstrom, 1996).

Research on support has been inconsistent in determining whether or not the perception of support availability influences individuals' evaluation of the quality of social support (Charmaz, 1983;Coyne, et al., 1986; Komproe, et al., 1997; Lakey \& Lutz, 1996; Ognibene \& Collins, 1998). Some studies have suggested that the perception of the availability and/or strength of support can influence the adaptation process in the methods or actions a person takes in the way they address their illness (Komproe, et al., 1997; Ognibene, et al., 1998). For example, Thoits (1995) mentions how the abundance of research focusing on perceived and received support tends to suggest that the belief of emotional support being available to an individual influences the mental health more so than actual receipt of support. This might suggest that if a woman who has lupus perceives emotional support being available, then the improvement in her psychological health may also benefit her physical health, since the immune 
system is designed to respond to threat or stressors. This is the premise behind 'stress-buffering' (Thoits, 1982) and is very applicable to the goals established for lupus patients by their doctors as a treatment method for lupus management. Stress reduction and 'buffering' are believed to greatly benefit managing lupus activity (Wallace, 2000).

Support from medical providers, in particular, is thought to be highly influential in the adaptation to illness (Dunkel-Schetter,1984; Drench, et al. 2003; Goldring, et al., 2003). This places medical and service professionals in an ideal position to impact a patient's coping with lupus, especially at the time of the diagnosis of lupus. Research conducted by Dunkel-Schetter (1984) on cancer patients and their reliance on medical providers for support, particularly emotional types, reinforces the importance of the medical providers in the adaptation process of patients. Most support studies identify adaptation to illness after an individual has received a diagnosis, but there is not a specific body of research that targets the adaptation that occurs during the process of receiving the diagnosis itself.

Determining the existence of an autoimmune disorder, in general, can be a long and drawn-out process. This often forces most patients to seek more than one physician for care and to possibly struggle through several years of frustration before, or if ever, receiving an official diagnosis. What an individual's experience is within the first few months of a diagnosis would seem to be an important factor to consider in learning more about a person's support 
needs. Consideration in the timing of support and one's health could be important in how it may improve later adaptation to a stressor such as lupus (Hoeksema \& Davis, 1999; McCracken, Semenchuk \& Goetsch, 1995; Smith et al., 1994).

A longitudinal study by McCracken, et al.(1995) on coping responses among individuals (men and women) with SLE recommends examining the additional variables and disease-specific differences on health and coping, including treatment history and disease activity, as it would relate to a patient's response to illness. The conclusions from this study suggest that there is an association between seeking support at one time and the health outcome at a later time. This indicates that individuals with lupus seem to show effects of support for longer duration and improved adjustment to illness from seeking support. Therefore, receiving a diagnosis may greatly affect a woman's immediate and future choices in seeking support. What the physician's provide in terms of support at that crucial time may influence these women later and for longer.

If support groups are generally believed to provide emotional forms of support to aid in the emotional responses to illness and develop networks with others who are facing the same stressors, then those who rely more on the instrumental forms of support would more than likely not benefit from the emotional forms or the additional network are not what they want. Previous research has suggested that individuals who perceive their social networks to be 
sufficient do not seek outside support sources (Sandstrom, 1996). This is one reason why recommendations in group participation given to lupus patients may actually do them more harm than good, particularly if they are seeking types of support not provided by these groups (i.e. instrumental forms such as financial assistance). As indicated in the previous study by McCracken, et al. (1996), the initial support seeking behavior is important in long-term adaptation to illness.

Support Group Participation and Health

For the most part, research points to possible benefits of support on health through group participation (Hurdle, 2001; Dunkel-Schetter, 1984; Gignac, 2000; Littrell, 1996; Sheldon, et al, 2000; Sandstrom, 1996; Dorsey, et al., 2004). However, the potential for negative experiences occurring could be just as likely as positive experiences are (Galinsky \& Schloper, 1977; Burg \& Seeman, 1994).

The field of psychoneuroimmunology and studies of stress effects on immune system function calls for closer examination of the role support groups play in the adaptation of health-challenged individuals (Littrell, 1996).

Researchers such as Helgeson \& Gottlieb (2000, p. 222) discuss the importance of designing support groups “...differently for people in different stressful circumstances... and with different coping styles." The primary thoughts behind the use of support groups, as a means of assisting the coping and adjustment to illness, is the assumption that being surrounded by peers in similar situations 
enables individuals to further develop important components of their existing social networks. Sharing experiences, peers providing helping behaviors to others in the group, and the element of social comparison among these peers within group settings are all aspects of the group processes thought to benefit participants. Studies on groups for individuals with MS indicate that a "response shift" among group members occurs when they shift their focus to coping skill development and the helping of others within the group (Schwartz, 1999; Schwartz \& Sendor, 1999). It is when they engage in the process of helping that they tend to become distracted from their own stress and develop a sense of purposeful activity, with action being the key word. As mentioned earlier with regards to coping strategies, there is some research that suggests interactive effects between talking about emotions and sense of control as they predict depressive symptoms (Ross \& Mirowsky, 1989). In order to provide beneficial support to all women with lupus, the groups would have to offer both. The current research on support groups explores the format, style, level and frequency of interventions that may be important factors in identifying beneficial effects on experiences and illness adaptation. However, there has been little comparison among the different types of groups in relation to each other. For example, some groups that are established to assist patients in coping with their illness are informal, self-help groups with no designated goals set for participants. Treatment groups have more structure, are led by trained professionals with restrictions in membership size and enrollment requirements. 
There is a risk, no matter what type of group, that the group structure and formats offered experiences may not meet the expectations of the participant. In a study by Galinsky \& Schloper (1994), individuals who were no longer participating in their support groups mentioned feeling overwhelmed and depressed with their group sessions. At these sessions, they listened to others talk about their disease progression, medical and legal problems, and emotional despair, which led to their decisions to discontinue attending because the match between what they were looking for and what they were receiving from the group was not beneficial to their own adjustment.

With lupus being as inconsistent and unpredictable as it is, one could only assume that a woman's support needs would be just as inconsistent. In order to meet these constantly changing needs, a great deal of work would have to go into coordination and evaluation of what support groups offer. Future research in exploring "who selects in and who selects out of support groups" (Helgeson \& Gottlieb, 2000) is needed in order to better understand the phenomena of group participation. Most group research focuses on those who participate and their experiences pertaining to their adjustment to illness. There is little research that provides insight into those individuals who do not participate in support groups and leads to the generalization that support group participation has something to offer to everyone. There are women with lupus who seem to be adapting well without participation and it is important to understand why in order to better understand the broader scope of other support 
sources women have to choose from.

Support group research neglects to fully explore the steps leading to the decision experience itself. Usually, those interviewed are existing members who already attend and the reasons of those who do not go unheard. Little research is available on the specific experiences among women with lupus, the social support types and sources they seek and the coping strategies that they rely on to adapt. Research needs to target the special needs of these women and distinguished the adaptation experiences from other illnesses that typically use self-help groups as support resources. Diseases such as cancer and HIV/AIDS utilize groups often as a means of support sources, but these involve different diseases and the assumption that those facing lupus also benefit from participation needs further investigation. 


\section{Methods}

The data for this qualitative study were drawn from interviews with women who volunteered to share their experiences regarding coping with lupus, social support, and group participation.

Recruitment

The initial recruitment phase began with contacting the group facilitators of four self-help support groups found to be in the general Portland area. The groups contacted were a core urban group (Portland); a group in the 'valley' area just outside the urban boundary (Newberg); a coastal group (Seaside/Warrenton) and a group approximately one hour drives from Portland (Salem). All of the facilitators were non-professional peers who had some materials provided to them by the Lupus Foundation of America Pacific Northwest chapter located in the state of Washington. They were asked to allow for time during the group meeting to present the study to the members. All four groups contacted for this project agreed to participate in recruitment and, since attendance at group meetings varied, the provision of the membership rosters from the Portland and Coastal groups to contact additional members was also discussed with the two group facilitators. These rosters tracked the members' attendances for a minimum of five years and provided the contact information of their members. The rosters were intended to be used as a way to recruit non-attendees who had never attended the group meetings and to contact them by phone. The 
Newberg and Salem self-help groups had only a couple of members who happened to be in attendance at the meetings during the presentations and no non-attendees to call. Therefore, a roster from these two groups was unnecessary and the facilitators agreed to keep the introductory letter on hand at the meetings in the event of any new members that either enrolled or attended meetings. The other means to recruit non-attendees was to encourage other members to mention the project and pass along the overview letter with contact information to women they knew with lupus who do not attend meetings.

The determination of what differentiated "attendees" and "nonattendees" was simply based on whether they had ever attended the meetings and by the way they described themselves. The other identifying requirements for eligibility in this project targeted diagnosis of lupus, age, and gender (female).

At each presentation, a letter of introduction was provided to the members in attendance that described the background of the researcher, the funding and research support sources, the general goal of the study and the details of what the study volunteers could expect in terms of time commitment, process and confidentiality. Each presentation was held in the evening and involved a brief overview of why this project was considered important to the lupus community. The presentations were designed to be open for discussion and questions among the members to contribute any suggestions or issues they believe should be included in the project. The presentations were concluded 
with sign up sheets sent around the table that members could sign at any time during the meeting. Contact information of the researcher and Portland State University was also given out through business cards and the letter describing the overview of the project.

There were two presentations given at each of the four groups and the average number of members in attendance at the group meetings was approximately five women. The Portland group had most of the members who signed up (eight members after the first presentation and six after the second presentation). All of those that signed up for the other two groups included in this study, Newberg and the Coast, were the same number of members who were enrolled. Others attending the meetings were generally spouses, siblings or parents were with a member providing support. The memberships to all groups were open-enrollment, free and predominantly female, which is the primary reason for the sample consisting entirely of women. Research shows that $90 \%$ of lupus patients are women, even though lupus does affect men. A couple of men did volunteer to participate, but they were told that the focus of this particular project was on women. They were assured that not being invited to participate by no means minimized the value of their experiences and that there could possibly be another lupus research project in the future.

Coinciding with the presentations, phone calls were made from the Portland membership roster to request participation by those who had never been to the meetings. Many of the names on the roster were no longer at the 
numbers listed and a few of the women who were contacted mentioned that they did not have time to participate in the interview. There were no refusals by women mentioning disinterest or anger about being contacted. Only ten calls were made from the Portland group roster and all those who signed up during the first meeting were contacted. Even though some of these women signed up and were initially interested, when contacted they seemed hesitant to follow through with their participation in the study mentioning that they were not sure if they were up to talking about lupus. Of the eight who first signed up, only four scheduled an interview with the others and requested a call back later which allowed them some time to consider participation. The roster from the coastal group was anticipated to provide more names and so it was not considered appropriate to call these women back with concern that it would create ill will. Even with the group facilitator efforts, there were those members who expressed being "tired" of talking about lupus "and nothing ever changing".

In addition to the roster calls and meeting presentations, there were calls received from four women who did not attend groups ("non-attendees"). They had heard about the project by word of mouth from current group members, a short announcement that was included in a monthly Portland group meeting flyer sent out by Legacy Health Systems and an announcement in the coastal groups monthly newsletter. All four of these women who called were participated in this study as non-attendees.

The initial recruitment sought to include 25 to 30 women ranging in ages 
between 20 and 50 years of age who had been diagnosed with systemic lupus erythematosus. Upon reviewing the sample guidelines and low enrollment numbers after the first round of meeting presentations and cold calls, the study recruitment process was revised to create a broader age range, health status that would include those awaiting a final diagnosis and incorporating all forms of lupus under one description. At the beginning of the recruitment process, the study was opened to those who had systemic forms of lupus without realizing that some of the women only identified themselves as having the discoid forms involving the skin. This point did come up during the presentation for the group at the coast where most of the members attending the presentation only had fibromyalgia and had not been diagnosed with lupus. Including all forms of lupus and incorporating these forms under the same description of S.L.E., as is done in the research, was initiated as an attempt to increase the sample size for this project. There was also the introduction of researcher disclosure that was believed necessary in order to increase the number of volunteers to take part.

Based on comments made by the women who hesitated to take part in this study, I thought that telling them of my own diagnosis would provide them some reassurance that their experiences were going to be listened to. Once group attendees and non-group attendees knew I had lupus, they were more interested in participating, including those who were initially hesitant after being contacted prior the revisions. Although there were still three volunteers who decided that they did not "feel up to" participating in the project, most 
commented that they felt "more comfortable" talking to someone "who could understand" what they were experiencing and stated their frustration in not being "heard" by those who don't have it.

These revisions led to an increase in the sample number and recruitment efforts continued until the grant funding deadline for the transcription services occurred. After the recruitment deadline, I received word from 15 more volunteers, both those that attended the four groups and women who did not attend groups, who were interested in participating in this study. Their names and contact information was taken for consideration to take part in future projects.

Sample characteristics

The final sample for this study consisted of 19 women in various stages and forms of lupus with one additional volunteer having been removed for not completing her interview before the grant funding period expired. The volunteers all identified themselves as having lupus during the sign-up. Understanding that a true diagnosis was difficult to achieve, this study included both those volunteers who had received an official diagnosis as well as those who had not been diagnosed with lupus by a physician or who had tests pending for a confirmed diagnosis. Those without the diagnosis considered their symptoms to be similar with lupus and/or their medical providers have already identified the possibility of them having an autoimmune disease like lupus. 
Therefore, these women identify closely with the illness and have assumed the condition as a means of seeking treatment options. The processes involved in receiving a diagnosis have a great deal to do with the timing of doctor appointments and lab work, similar to playing the lottery. When you arrive at the doctor's office, you have a tendency to really hope for great numbers. To have withdrawn these volunteers would have dismissed a crucial element in studying illnesses such as lupus. Fifteen of the participants in this final sample were diagnosed with lupus in some form and four were still waiting for confirmation of a diagnosis at the time of this study. Of these four, one study participant had decided to abandon seeking medical care due to the emotional toll not receiving a diagnosis was taking on her.

The sample consisted of 19 women ranging in ages from 28 to 62 years of age and the table below (Table 1) identifies the age groups involved in this study. There were no interviews conducted from the Salem group:

Table 1

Age Ranges of Study Participants

\begin{tabular}{cccccc}
\hline Group & $20-29$ yrs & $30-39$ \rs & $40-49$ yrs & $50-59$ yrs & $60-69$ \\
\hline Portland & 1 & 2 & 4 & 1 & 1 \\
Coast & - & - & - & 1 & 1 \\
Newberg & - & - & 1 & - & - \\
Salem & - & - & - & - & - \\
Non-attendees & 1 & 3 & 1 & 2 & - \\
\hline Total: $(\mathrm{N}=19)$ & 2 & 5 & 6 & 4 & 2
\end{tabular}


Two participants were in their twenties; five in their thirties; six in their forties; four in their fifties; and two in their sixties with an average age of 45 years. The women were designated into two categories: 'attendees' and 'nonattendees'. There were 12 attendees and 7 non-attendees who participated in this study. Three out of the total four groups were included in the interview process. One group (Salem) was involved only during the participant observations, but no interviews were completed due to a lack of volunteers.

Of the 19 study participants, 12 were married, re-married or in committed relationships; five were separated or divorced and two were single. Eighteen out of 19 volunteers had either taken some college classes, received college degrees or trade certification. There were eight who identified themselves as employed; seven were either not working (outside the home, retired, or did not divulge details of their means); and four mentioned they were receiving disability income. The majority (17) of participants identified themselves as Caucasian; one volunteer was African-American and another was Japanese-American (Table 2). 
Table 2

Demographic Information of Study Sets

\begin{tabular}{|c|c|c|c|}
\hline Demographic Data & $\begin{array}{c}\text { \# of Attendees } \\
(\mathrm{N}=12)\end{array}$ & $\begin{array}{c}\text { \# of Non- } \\
\text { Attendees } \\
(\mathrm{N}=7)\end{array}$ & $\begin{array}{c}\text { Total } \\
\# \\
(\mathrm{~N}=19)\end{array}$ \\
\hline $\begin{array}{c}\text { Married/In a } \\
\text { Relationship }\end{array}$ & 8 & 4 & 12 \\
\hline Separated/Divorced & 4 & 1 & 5 \\
\hline $\begin{array}{c}\text { Single/Never- } \\
\text { Married }\end{array}$ & - & 2 & 2 \\
\hline $\begin{array}{c}\text { College/Trade } \\
\text { School }\end{array}$ & 11 & 7 & 8 \\
\hline Employed & 5 & 3 & 4 \\
\hline Disability & 3 & 1 & 7 \\
\hline At-home/Retired & 4 & 3 & \\
\hline
\end{tabular}

Of all four groups, only the Portland group was identified specifically for women with lupus. The other three included membership for women with fibromyalgia and distinguished their group as a "fibro and lupus group". The Portland group recognized members who had both, but did not include fibromyalgia in their support group name. The meetings were held in rooms at the following local hospitals:

- Good Samaritan in Portland

- A local church in Newberg

- Kaiser Permanente in Salem

- Providence Seaside Hospital 
The general format of all the four group meetings is commonly referred to by facilitators as "caring and sharing". After brief reviews of the agenda, the facilitators opened up the meetings to the members to discuss anything they wanted to talk about. The two largest groups (Portland and the Coast) had meeting agendas with speakers from local medical groups, nutritionists, naturopaths, and chiropractors who speak on services that pertain to those with lupus. The attendance rates for both of these groups were similar even when speakers were on the agenda and the coastal groups was the only one that held meetings in the afternoons. Finally, the coastal group prefers to act independently of the LFA in terms of membership, community fundraising activities and group guidelines. This group is a registered non-profit and mails out a monthly newsletter that spans international boundaries. In addition, the coastal group hosts a website, web group and only requests donations to assist in covering the newsletter printing costs and postage.

Of the 19 study participants, 16 were lived in the Portland metro area; two from the coast; and one member lived in the Newberg area. There were members in all groups that traveled in from outside the city limits or in the suburbs. This project uses the descriptive terms 'urban' and 'rural' loosely as a way to distinguish the overall location of the groups in the study. Some members attended both the Portland and the Coastal group on occasion, particularly when speakers were presenting, just to find out what they were offering. Generally, attendees identified with the group within their home 
location.

Data collection

There were three components of the collection of the data including the guided interviews, the gathering of various literatures from groups or individuals participating in this study and notes/journal entries.

The types of questions included in the interview guide were designed to explore basic demographics, health status, views on the quality of medical care received, social and emotional support sources, types of support received or sought, available networks, sense of community and the services/resources they relied upon. The interview guide focused on the reasons that led them to either participate in a peer-led self-help support group or not.

All study participants were interviewed using a guided format for the conversation, which lasted as long as the volunteer cared to share. On an average, the interviews lasted about one and one-half hour with some interviews lasting for two to four hours. The guide was split into two general sections (demographic/diagnosis and support) and a skip pattern format followed which directed the conversation towards the appropriate questions for either the group attendees or the non-attendees. Study participants were given the option of stopping the conversation at any time during the interview. The interviews were primarily conducted in a restaurant or a library and occurred between April and August of 2004. Occasional phone calls were made to the participants during 
that time period to follow-up on points that were raised during the interviews for clarification purposes. Two interviews had minor complications including a malfunction in the recording device (leading to re-scheduling another interview) and an interruption requiring relocation of the scheduled interview. One interview from the Salem group was eliminated from analysis early in the data gathering process due to re-scheduling difficulties.

There were a total of 45 open-ended questions in the guide used for this study (See Appendix A), which were based on the interview questions used by Sandstrom (1996) in his study of HIV/AIDS support group participation. These questions cover a spectrum of experiences that are applicable to the similar processes of loss and adaptation that women might also be confronted with. The guide was organized into three primary sections that addressed particular research questions: Preliminary, Diagnosis and Involvement in Support Systems. The guide asks some closing questions which invited study participants to provide feedback and recommendations about the interview process and/or guide. An additional question was included to encourage the study volunteer to reflect on their self-image in relation to lupus. This question was designed as a means of closing the conversation and easing into the end of the interview process. It was added so that if the volunteer had anything else they wanted to address, this reflection would give them the chance to still contribute that information without having to return to an earlier section of the instrument. The Brief CIRS referenced in the interview guide was an additional 
component of the project that had to be removed due to budget restrictions. Ideally, it would have provided further verification of the data, discussed further in the conclusion of this paper.

Within each section, there are separate areas of interest that further explored the volunteer's experiences. In the Preliminary section, there were questions that addressed the demographics of the participant; questions on the illness discovery process and her previous knowledge of lupus prior to their own diagnosis; her family history with autoimmune diseases; her current health/disease status; and whether there were any other illnesses that she was facing in addition to or arising from lupus.

The Diagnosis section covered questions which sought information about the overall impact that the diagnosis or lack thereof, had on the volunteers' lives and was divided into the two sub-sections previously mentioned: impact of diagnosis and social support. The impact questions explored the diagnostic experience in general; the support received in social and instrumental forms from their medical providers; and the reactions they experienced from those with who they shared their diagnosis (e.g. family members, friends, co-workers).

The social support section asked the participants to consider their experiences following their diagnosis and to describe their current levels of support, their support needs and preferences regarding the type they rely on the most, any changes in relationships and other support sources such as work and community which they had available to them. 
The Involvement section began with general questions about support groups regarding how they were introduced to groups and who gave them the information; what their initial reasons were for attending the first meeting and whether they had participated in any type of support groups before the lupus group. The last question then directed the researcher in a skip pattern to the next set of questions based on whether the study volunteer was currently a group participant or not. For the group participants, the volunteers were asked to discuss their experiences in participating, what types of support they received; their attendance patterns; the effects on any adaptation, relationships, or selfconcept; and what other sources besides the group they relied on to help them cope with their illness. The questions for the non-group participants focused on the other sources they have available for support; their views on groups in general; what types of support they would look for from a group; and whether they would ever consider participation if some of their expectations were addressed.

The literature from groups including newsletters, meeting flyers, informational handouts and other information from those who did not attend groups (i.e., websites, research articles) were compiled over the duration of the project. This information was used to identify meeting agendas, local resource and services available, and to gain insight into the types of issues currently on the minds of study participants.

I was also able to attend all four self-help groups in this study as a 
participant observer. During the meetings, I made observations of the group dynamics and processes, topics of discussion, attendance numbers and noted any particular references to, complaints about or requests for support. Notes were organized by attendees and noon-attendees and group locations in order to be easily compared with the case files developed through the Ethnograph software program.

Finally, I have been fortunate to join in conversations with some of the participants of this study over the years, which gave me a unique and wellinformed perspective during this study. Personal journal entries were written over a period of seven years based on conversations and social activities spent with a few of the study participants before and during the study. It could be argued that the proximity of my own perspectives were too close to the subject matter to provide verification of the data. However, there were times that the study participants were unable to express or verbalize their thoughts due to the general confusion common to those with lupus and caused by medication or disease. It seemed helpful to them to have specific prompts that triggered their line of thinking, which someone with lupus would be very familiar with. The context in which the responses or expressions were made was important when coding and categorizing the data. Therefore, the immersion of my own personal experience provided me with a level of expertise in this area of study and the background to fairly represent their experiences. 


\section{Analysis}

The analysis of the data involved a combination of three methodologies: Grounded Theory (Charmaz, 1990; Creswell, 1998; Strauss \& Corbin, 1998); ethnography (including Ethnograph software) and phenomenology. This project incorporated elements from all three in order to analyze the data from a broad perspective.

The interviews for this study were conducted by the primary researcher using audio-tape and were transcribed by a professional transcriptionist whose services were financially supported through a grant from the Northwest Health Foundation located in Portland (see Appendix B). The transcription by an outside source was a means of minimizing potential researcher bias within the time and financial constraints of this project.

Upon completion of the transcriptions, the interview data were entered into the Ethnograph software program (V5.0) to be coded and categorized. The codes were specified as type, source, identifier, and levels in order to later group into segments for a broader picture. The 27 parent codes were structured into a By using this qualitative software, the data was able to be organized, searched, located and combined with other codes to determine patterns. Development of 'case files' were also possible and used for comparisons between the two sets of study participants.

In addition to the software, elements of Grounded Theory (Strauss \& Corbin, 1998), phenomenology and ethnography (Creswell, 1998) 
methodologies were incorporated. The scope of this project did not allow for an entirely new theory to be developed, which is the premise of Grounded Theory methodology. By using components of this method, however, the experiences shared by the study participants are used to 'shape' the data collection process thereby creating an overall vision into the realities of those who participate in the study. Rather than prove or disprove hypotheses as in conventional methodologies, grounded theory is a picture developed out of the process of investigating experiences.

Ethnography and phenomenology methodologies included observing, interpreting, documenting and recording. In ethnographies, the underlying principle is to investigate systems within cultural or social groups. This was done through the participant observations of the self-help groups in this study. Phenomenological studies center on describing the meanings of the experiences reported by the study participants. This method was utilized in the journal entries of both the interview processes as well as the personal journal entries of this researcher.

Once all of the data were collected, codes were developed through constant comparison techniques and categories developed presenting the major themes identified. These thematic categories were used to respond to the existing research laying the foundation of this study and included: 
- diagnostic process and personal descriptions of experiences

- social support (types and sources)

- coping strategies (emotion-, problem- and relationship-focused)

- reasons for participation and reasons for not participating

The codes used in this project were designed to represent as many aspects of the discovery process pertaining to behaviors, sources, types, timing, details, levels, locations and interpersonal aspects to the illness experience. Although not conclusive, these identified codes were used to target specific areas considered to be important in representing their experiences. The following are some examples of the codes used in this project (Table 3):

Table 3

Major Codes Used in Data Analysis

\begin{tabular}{|c|l|l|}
\hline $\begin{array}{c}\text { Code } \\
\text { (Dimensions) }\end{array}$ & \multicolumn{1}{|c|}{ Definition } & \multicolumn{1}{c|}{ Example } \\
\hline $\begin{array}{c}\text { Diagnosis } \\
(2)\end{array}$ & $\begin{array}{l}\text { A diagnosis of lupus has } \\
\text { been made by a medical } \\
\text { provider }\end{array}$ & $\begin{array}{l}\text { "I got my diagnosis } \\
\text { about a year and three } \\
\text { months ago..." }\end{array}$ \\
\hline $\begin{array}{c}\text { Concern } \\
(3)\end{array}$ & $\begin{array}{l}\text { Coping strategy at diagnosis: } \\
\text { emotion-, problem-, and } \\
\text { relationship-focused coping }\end{array}$ & $\begin{array}{l}\text { "My first concern was } \\
\text { finding someone that } \\
\text { would refute that book } \\
\text { from 1952 that said I } \\
\text { was going to die." }\end{array}$ \\
\hline $\begin{array}{c}\text { Source } \\
(10)\end{array}$ & $\begin{array}{l}\text { Sources of support such as } \\
\text { medical, family, internet, } \\
\text { organizations, books }\end{array}$ & $\begin{array}{l}\text { "My family is really } \\
\text { supportive." }\end{array}$ \\
\hline $\begin{array}{c}\text { Type } \\
(6)\end{array}$ & $\begin{array}{l}\text { Types of support such as } \\
\text { financial, medications, } \\
\text { listening, information }\end{array}$ & $\begin{array}{l}\text { "..even physical } \\
\text { support like helping me } \\
\text { out and that sort of } \\
\text { thing..." }\end{array}$ \\
\hline
\end{tabular}


The results from the coding process provided the groundwork for the development of themes. These themes were more fully developed with the use of my research notes and journal entries derived from the participant observations made during the group meetings I attended. This information described topics of conversations, numbers of those in attendance, identifying the types of coping strategies mentioned or used by attendees as a means of dealing with their particular situations (definitions of these strategies were based on the definitions used in current coping research). After the each interview, memos were written and later added during the formulation of categories.

All of the names of the volunteers in this study are pseudonyms. 


\section{Results and Discussion}

A comparison between the women who attend lupus support groups and those who do not attend was the primary goal of this project. The discussion of the results from this study will be organized using the research questions from the beginning of this project. These questions were designed to target some key reasons about participation choices. Specifically,

1) What are the main reasons that lead them to or keep them from group participation?

2) What, if any, differences can be found between those who do attend and those who do not attend self-help groups? (e.g., diagnosis, coping strategies)

3) What types and sources of support do they seek in their adaptation to lupus?

Preliminary review of the data showed some information about their

prior knowledge of and history with lupus, which may be important factors to consider in understanding more about women's choices in social support and their coping strategies. Before discussing the social support needs in relation to lupus group participation, some of their personal histories give important insight into who they are.

Nine out of the 19 study participants interviewed had some prior knowledge of lupus through media, campaigns or through people they knew (five attendees and four non-attendees). Eleven mentioned a family history of autoimmune diseases such as MS, rheumatoid arthritis (RA), and fibromyalgia. 
Out of those 11 , seven had a direct female relative with lupus. The majority of those with lupus in their family were the women who attended support groups. One participant mentioned an aunt and a cousin with MS, another set of an aunt and cousin with fibromyalgia, her father has MS and she herself is currently facing RA and lupus. Some of the study participants were unaware of their family history until their own diagnosis. The participants who mentioned awareness of lupus were not the same who had a family history. They knew of family members being ill and having unusual symptoms, but they rarely made a connection between their relatives and their own illness.

The mentioned the media and fundraising campaigns as common sources for their prior lupus knowledge The slogan used by the Lupus Foundation of America (LFA), "Someone You Know Has Lupus", is an effort to inform the general public of how we are all connected to lupus in some way and are probably unaware of it (e.g. family, work, neighborhoods).

All of the women had other conditions, referred to in this study as crossover conditions, which they attributed their health problems to before lupus. The diseases, including multiple sclerosis (MS), sjogren's syndrome, raynaud's phenomenon, fibromyalgia and rheumatoid arthritis (RA), are autoimmune conditions which show similar symptoms as lupus. In fact, a majority of the women in this study had been diagnosed with fibromyalgia, a form of connective tissue inflammation characterized by chronic pain and fatigue. 
The summary below helps to organize the informational picture prior to the participants' receipt of their diagnosis or their health history. The most important information drawn from this part of the interview is that $100 \%$ of the entire study sample ( 12 out of 12 attendees and 7 out of 7 non-attendees) had other conditions besides lupus (Table 4):

Table 4

Experiences Prior to and After Receiving Lupus Diagnosis

\begin{tabular}{|c|c|c|c|}
\hline $\begin{array}{c}\text { Study } \\
\text { Participant } \\
\text { Set }\end{array}$ & $\begin{array}{c}\text { \% With Prior } \\
\text { Knowledge of } \\
\text { Lupus } \\
\text { (within sets) }\end{array}$ & $\begin{array}{c}\text { \% With } \\
\text { Family Health } \\
\text { History } \\
\text { (within sets) }\end{array}$ & $\begin{array}{c}\text { \% With } \\
\text { Crossover } \\
\text { Conditions } \\
\text { (within sets) }\end{array}$ \\
\hline $\begin{array}{c}\text { Attendees } \\
\text { (N=12) }\end{array}$ & $42 \%$ & $67 \%$ & $100 \%$ \\
\hline $\begin{array}{c}\text { Non- } \\
\text { Attendees } \\
(\mathrm{N}=7)\end{array}$ & $57 \%$ & $43 \%$ & $100 \%$ \\
\hline
\end{tabular}

Getting to "Yes"

The diagnostic experience is the initial step that forces a woman to move away from who she knows herself to be toward someone who now has to become familiar with herself all over again. The process towards a diagnosis was not always an easy one to get through. Some of them had to confront several different medical providers until they finally met with one who showed initiative in working toward some answers. A common scenario described by 
the participants was an experience with a physician who dismissed their symptoms:

"I finally started seeing doctors for it. The first doctor I saw told me I was a hypochondriac..." (Julie, non-group attendee)

"... when I went to [ ], they told me I was neurotic, but I told them there had to be something more than that..." (Rhonda, group attendee)

For some, the lab results were inconclusive or inconsistent, leaving them without answers to what they were experiencing, despite the fact that they knew something was very wrong. A few experienced this diagnostic scene more often than they would have liked to:

"... I got first diagnosed [sic] in '85 and I was never treated for it. My doctor initially denied that I had it because I didn't have the Mylar rash. And then I got re-diagnosed in 1997." (Carrie, attendee)

"Sometimes your doctor will say, 'Yep, you got it'. Sometimes he 'll say 'No, you don't'." (Aimee, non-attendee)

"They gave me a diagnosis definite and then they told me I had six months or less to live and get my affairs in order...And then, six months down the road my doctor in Dallas couldn't find it showing up in my blood work so he said 'Well, I don't think you've got lupus.' And that threw me into thinking I was crazy." (Teri, attendee)

One would assume that, if there was a conclusive history of lupus in one's family, the diagnostic process would have been easier. Yet, the participants who had a history of lupus in their families still have or did run into problems getting a firm diagnosis. There were some who mentioned that they had a physician who refused to make a serious health connection even after they were told of their history: 
"One of the comments had been about [that] I had told him that my sister had it, and 'Well, I'm sure that your sister gets a lot of attention now that she has lupus, '...like I am trying to seek a diagnosis so I can get attention from my family" (Ellen, non-attendee; not yet diagnosed)

As they pursued the support of physicians and struggled with trying to gain the acknowledgement of their pain, fatigue and strange symptoms from those close to them, the frustration from their physical and emotional burdens grew. One participant very concisely summed up her experience of a new evolving identity and a disconnect to her old self reflected in a number of women's stories and echoing the research by Charmaz (1983):

"I was feeling a sense of loss of myself as who I was." (Cheryl, attendee)

The most important source of support at the time of the initial diagnosis by all study participants was the medical provider. Their personality make-up and where they were emotionally, in addition to how many physicians they had met prior to the diagnosis, had some influence on their initial response to the news. What was said or done by the attending physician at that moment may have been instrumental in deciding their first steps towards their adjustment:

“...we've all had that experience where somebody finally just kind of throws up their hand and pats you on the head and says, 'How is your sex life, sweetheart?' And they want to ask you, 'Is everything okay at home' as if 'Yes, my husband is philandering on me, so gee I don't know what else to do about it, so I think I'll come up with a disease'! Like that happens!" (Aimee, non-attendee) 
"... when I had my appointment on the 19th, she called me in and she said, 'Okay. Here's what we know.' And she said, 'You have Lupus.' And I sat there and she just kept looking at me. And she said, 'Are you sure you're okay?' I said, 'Yeah!" (Laurie, group attendee)

Out of the 15 volunteers who had received a diagnosis (11 attendees and 4 non-attendees), six attendees described their diagnostic experience as 'difficult' and five described their experiences with having 'no complications'. As for the non-attendees, three of them described their diagnosis as 'difficult'. As shown in Table $3,100 \%$ of the entire study sample ( 12 out of 12 attendees and 7 out of 7 non-attendees) had other conditions besides lupus that can contribute to confusion over symptoms, the causes and treatment plans.

With every rejection or dismissal, these women experienced at one time or a lack of belief in themselves. Some of the women expressed feeling depressed and eventually decided not to continue to seek medical attention. They surrendered to coping with their pain alone, choosing to risk dying over continuing the battle for medical treatment. They were not denying illness, but simply felt that it was easier to 'quit' than go through more inconclusive lab work and disappointing doctor appointments. Some of the study participants were able to receive a diagnosis readily due to the severity of the disease progression and/or because of a prior history of other autoimmune diseases taken seriously by their physician:

"I went to the doctor and so the following Monday, it might have been a Tuesday, went to the doctor and they knew immediately that my kidneys weren't functioning properly and I was spilling a lot of protein. The diagnosis was 'you have Lupus'." (Mary, participant) 
This study sought to learn more about their initial reactions, or the recollection of these reactions, once they had received a confirmed diagnosis. Some women took their diagnosis to their employers, relatives, friends and spouses as a mean of showing them that their poor health wasn't 'all in their head'. A few of these women felt a tremendous sense of relief to be able to label the physical and emotional chaos they had been experiencing:

"Actually, it's a relief though because you think you're crazy. And then when they put a name on it and they kind of explain some of the crazy things that have been going on with your body, it's a relief. Because I really did think I was going nuts, losing my mind." (Joanne, attendee)

However, a diagnosis could also be a double-edged sword. The relief of finally identifying the reasons for their discomfort and pain was sometimes short-lived as the realities of their new challenges sunk in.

Coping: The Journey Begins

The initial concerns that the participants recalled at the time of their diagnosis fell into three main arenas and grouped into the coping strategies: 1) problem-focused, 2) emotion-focused; and 3) relationship-focused. The definitions of these strategies were based on previous research in coping and are described in Table 5 as follows: 
Table 5

Coping Strategy Definitions

Strategy

Definition

Examples

and Dimensions

\begin{tabular}{|c|c|c|}
\hline Emotion-focused & $\begin{array}{l}\text { Strategies that attempt to } \\
\text { alter emotional response } \\
\text { to a stressor, condition or } \\
\text { situation }\end{array}$ & $\begin{array}{l}\text { - } \text { counseling or therapy } \\
\text { - humor } \\
\text { - denial or avoidance } \\
\text { - faith } \\
\text { dance }\end{array}$ \\
\hline $\begin{array}{l}\text { Problem- } \\
\text { focused }\end{array}$ & $\begin{array}{l}\text { Strategies that target the } \\
\text { source of the stressor } \\
\text { (lupus) }\end{array}$ & $\begin{array}{l}\text { - change work schedule } \\
\text { - review health insurance } \\
\text { coverage } \\
\text { - } \\
\text { - rearch internet for information } \\
\text { register with lupus organization }\end{array}$ \\
\hline $\begin{array}{l}\text { Relationship- } \\
\text { focused }\end{array}$ & $\begin{array}{l}\text { Strategies that focus } \\
\text { attention on the relations } \\
\text { within one's } \\
\text { family network }\end{array}$ & $\begin{array}{l}\text { - Revaluation-adapting scope of } \\
\text { values } \\
\text { - Containment-of illness from } \\
\text { affecting others } \\
\text { - Network remodeling- } \\
\text { adding or removing } \\
\text { relationships } \\
\text { - Adaptation-modifying } \\
\text { 'companionate activity' } \\
\text { - Reciprocity-attention to well- } \\
\text { being of significant others } \\
\text { - Communal-shared adaptation } \\
\text { with loved ones }\end{array}$ \\
\hline
\end{tabular}


Once the women were given their diagnosis, the responses they recalled during the interviews illustrated some differences in the strategies they relied on to cope. As previously mentioned, the women had additional illnesses, family history of autoimmune diseases and different experiences in the diagnosis process that played a part in their responses.

The 15 study participants diagnosed with lupus were asked about their initial concerns at the time they were told and coded into the three coping strategies (Table 6).

Table 6

Coping Responses at Time of Diagnosis

\begin{tabular}{|c|c|c|c|}
\hline $\begin{array}{c}\text { Total Coping } \\
\text { Responses }\end{array}$ & Emotion-focused & Problem-focused & $\begin{array}{c}\text { Relationship- } \\
\text { focused }\end{array}$ \\
\hline Attendees (11) & $55 \%$ & $27 \%$ & $18 \%$ \\
\hline Non-Attendees (4) & $50 \%$ & $50 \%$ & - \\
\hline
\end{tabular}

The mention of emotion-focused coping strategies at the time of diagnosis was anticipated to be more likely among those women who were identified as 'attendees' based on the premise that those who attend support groups are seeking more emotional forms of support. Although the nonattendees were expected to show some emotion-focused strategy usage, my assumption was that their reliance on problem-focused coping strategies would 
be one reason for their decision to not attend self-help groups which I believed to offer more emotional types of support. As Table 6 suggests, the attendees did state more reliance on emotion-focused strategies. The non-attendees, however, were split between emotion- and problem-focused with no mention of relationship-focused responses.

Most of the responses by both attendees and non-attendees to the question regarding initial concerns at diagnosis were not typically considered emotion-focused strategies addressing action. They were predominantly addressing their emotional reaction to the diagnosis and stated little behavior to address their emotions in response to their illness. Although their concerns of death and dying were clearly reactionary, some of the descriptions and contexts in which these statements were made did indicate that there was more occurring than just emotional purges. Some of their reactions seemed to be taking a personal inventory of the emotions going on within them and then a period of evaluation of what their future would be like without mentioning any specific plan of action. In other words, there seemed to be a combined approach used by all the women that involved emotional reaction leading to problem-focused coping, but was stalled by an evaluation period:

"Well, at that time, actually, I guess you could say I was more relieved because I finally knew what I was dealing with. The only worry or concern I had would be my quality of life..." (Donna, attendee)

For example, one study participant recalled her diagnosis by describing 
what seemed to be a predictive assessment of her future with lupus, but did not elaborate on specific strategies she was going to use to meet the new challenges:

"This was so totally foreign to me. And here I am dealing with this - I've got two kidneys and now I have this involvement because of this disease. And what is it going to do to me? And how is it going to-I mean I can look back at it now and think - these were all things I probably was thinking about but not saying out loud. There was fear. There was total fear that I could end up really sick; that I could end up on dialysis; that I would look at a kidney transplant. I projected that far out." (Laurie, attendee)

In essence, even though there was the underlying emotion of panic and fear, she was thinking, planning, and anticipating her future actions or experiences. As she herself said, "Fear is a great motivator". Her emotional reaction to the diagnosis seemed to be the beginning of a more complex process including an 'incubation' period of evaluating all the angles before an action was chosen. This type of response also occurred among the non-attendees, although not as often, leading to question if the presence of the evaluation phase was due to the receipt of the news and clouds what strategy they actually used.

In order better understand the responses of all the study participants, a second analysis of all coping strategies expressed throughout their entire interviews was completed in order to develop a sense of their current coping responses. The women who had not yet received a diagnosis were included in this analysis because their health challenges also require utilizing coping strategies as they continue to seek an official diagnosis.

The strategies expressed by all study participants, including those 
women who have not yet received a diagnosis, did seem to reinforce the earlier results regarding the attendees relying on more emotion-focused strategies (Table 7). However, the responses by the non-participants throughout their interviews show more use of relationship-focused strategies, which indicates that they are more likely to turn to relationship-focused avenues as a means of coping rather than the emotion- or problem-focused strategies. This implies that their strategies for coping with illness are more based on their relationships within their family units than addressing their feelings about lupus or using specific actions to target the lupus.

Table 7

Coping Responses Mentioned During Entire Interview $(\mathrm{N}=19)$

\begin{tabular}{|c|c|c|c|c|}
\hline $\begin{array}{c}\text { Coping } \\
\text { Response } \\
\text { (\# of total } \\
\text { responses) }\end{array}$ & $\begin{array}{c}\text { Attendees } \\
(\mathrm{N}=12)\end{array}$ & $\begin{array}{c}\text { Non-Attendees } \\
(\mathrm{N}=7)\end{array}$ & $\begin{array}{c}\% \text { of } \\
\text { Attendee } \\
\text { Responses }\end{array}$ & $\begin{array}{c}\% \text { of Non- } \\
\text { Attendee } \\
\text { Responses }\end{array}$ \\
\hline $\begin{array}{c}\text { Emotion- } \\
\text { focused } \\
(153)\end{array}$ & 102 & 51 & $42 \%$ & $30 \%$ \\
\hline $\begin{array}{c}\text { Problem- } \\
\text { focused } \\
(84)\end{array}$ & 48 & 82 & $38 \%$ & $48 \%$ \\
\hline $\begin{array}{c}\text { Reeationship- } \\
\text { focused } \\
(175)\end{array}$ & 93 & 170 & $100 \%$ & $100 \%$ \\
\hline $\begin{array}{c}\text { Total \# and \% } \\
\text { of Responses }\end{array}$ & 243 & & $20 \%$ & \\
\hline
\end{tabular}

Emotion-focused coping

To cope with lupus in general, the attendees described emotion-focused actions including self-help group attendance, faith-based organizations and some 
avoidant behaviors like denial:

"I'm a Christian and I practice my faith. And I know how important it is to keep practicing your faith" (Cat, attendee)

"...went deep into denial. It was like, "No. There's no way I can have that. I'm fine." (Joanne, attendee)

One respondent used her journal as a way of monitoring her emotional coping strategies by comparing her adjustment to lupus over time, mentioning a sense of accomplishment, as well as something she says represents to those who might read it o story of her legacy with the illness:

"...my journal is there for the world and I think it also gives you a reason to go back and look and say, 'I'm having a bad day. Let's go back and look.' And I did that after that meeting. It was really interesting to see how I had dealt with things and how I have changed to make it better." (Laurie, attendee)

Since they do not attend support group meetings, this may have been one of the first and only times some of the non-attendees had ever sat down to discuss what they had experienced outside of their social network or physician. During the interview process, there were a couple of women from this set of participants who became emotional and did say that they had not really talked about having lupus until then. Some of these women expressed little opportunity to really talk to anyone about what they are going through, even though they described their social support sources as "good" or better. The emotion-focused strategies mentioned by these women were similar to the strategies mentioned by the women who did attend the lupus self-help groups: 
"I'll just blow it off or I'll just say, "Oh, my hand hurts," but I won't go into why. Just because I'd rather not deal with it."

(Ellen, non-attendee)

"Faith. The big people upstairs, and have constant conversations; on-going conversations, conversational prayer."

(Julie, non-attendee)

"I think we get stressful moments where I break down like this, things are going well. Stress is a huge factor so I've learned just to let the little things go." (Reese, non-attendee)

Problem-focused coping

The types of statements made by the non-attendees were more focused on their attempts at gaining control of their health or improving their knowledge regarding lupus or their treatment options. Whether is addressing the physical challenges imposed by lupus or the challenges brought on my outside sources, such as employment or the environment in which they live, non-attendees showed a strong determination to maintain a sense of normalcy in their daily living:

"Well, one thing that I've done for my joints, and it's not so much for the joint pain itself because I still get it, is working out. Because one, when I was overweight, I know that while it wasn't causing the joint pain I know that it wasn't helping it either, and was probably aggravating it and making it worse... by working out I would also prevent any atrophy or prevent any disintegration; so not wanting that to happen. I've been doing that." (Ellen, non-attendee)

I tried my hardest to make the job work. I would wash my clothes in the Sunguard stuff. I wore all this protective stuff, everything, but it was too much." (Nancy, non-attendee) 
Nancy spoke at length about her struggle to remain working as a postal carrier and walking a strenuous route. She fought the administrative barriers being placed on her by the post office as she tried to find a position with them that would not require her to be out in the sun, which caused her skin to break out in rashes and brought on extreme fatigue. She has since left the post office, but they have refused to 'fire her' apparently concerned with legal action she may bring on due to the lupus.

Most of the non-attendees took a very strong lead in educating themselves so that they could take part in the decisions regarding medication and treatment alternatives. Many of them would phrase their statements in ways that showed a sense of accomplishment, determination and self-care.

The attendees mentioned knowledge and education, as well. Unfortunately, there were also a few truly desperate acts they resorted to in order to cope with their stress:

"And then all of a sudden I knew I was dealing with a potentially fatal disease. After I got home I started looking everything up. I've got to know more." (Carrie, attendee)

"I got a job managing a large complex in a really nice neighborhood. I always had the selection and I enjoyed that. It only lasted for about six months because I got sick. So that was the case and then I had to send the children to my in-laws and I had to go and just live by myself in a one-room thing. It took me a year to recover enough and I had to go back and do it all again." (Teri, attendee)

"When I found drugs, illegal drugs, I went back to work." (Rhonda, attendee)

The major theme in the problem-focused strategies used by the attendees 
was in their knowledge about medications, physicians, and treatments of lupus. They were also very knowledgeable about other conditions and belonged to organizations related to health.

The non-attendees do use more problem-focused coping compared to the attendees, but these results do not explain why these women do not attend the groups. The final coping strategy category examined is relationship-focused.

\section{Relationship-focused coping}

The relationship-focused coping strategies were categorized into six dimensions of the coping strategy in order specifically identify the types of strategies used by both sets. The relationships targeted by this strategy are those involving close family and significant others within one's social network. The dimensions of these relationship-focused strategies are described below:

1) Relationship adaptation- where the family members make accommodations to help out with chores and duties)

2) Communal coping - "its our problem together"; shared responsibilities

3) Containment of illness- doing what is required to manage the disease so that it doesn' $t$ cause interference with home life

4) Relationship reciprocity- making sure accommodations within relationships are fair

5) Network remodeling- adjusting network to include those individuals perceived as supportive

6) Revaluation of self and relationships- monitor quality of relationships and what self is contributing to them 
It was anticipated that the women who attended lupus support groups would show more inclination to rely on relationship-focused strategies, as they were more inclined to be accustomed to a group perspective. In Table 6, the results show that the non-attendees mentioned more relationship-focused coping. The results are specified further in Table 8 presenting the responses categorized within the six dimensions of this coping strategy:

Table 8

Relationship-focused Coping Responses (\# of Responses)

\begin{tabular}{|c|c|c|c|c|}
\hline $\begin{array}{c}\text { Total Number } \\
\text { of Responses } \\
\text { per Dimension }\end{array}$ & $\begin{array}{c}\text { Attendees } \\
(\mathrm{N}=12)\end{array}$ & $\begin{array}{c}\text { Non- } \\
\text { Attendees } \\
(\mathrm{N}=7)\end{array}$ & $\begin{array}{c}\% \text { of } \\
\text { Attendee } \\
\text { Responses }\end{array}$ & $\begin{array}{c}\% \text { of Non- } \\
\text { Attendee } \\
\text { Responses }\end{array}$ \\
\hline $\begin{array}{c}\text { Adaptation } \\
(22)\end{array}$ & 11 & 11 & $12 \%$ & $13 \%$ \\
\hline $\begin{array}{c}\text { Communal } \\
(31)\end{array}$ & 16 & 12 & $18 \%$ & $18 \%$ \\
\hline $\begin{array}{c}\text { Containment } \\
(26)\end{array}$ & 14 & 17 & $20 \%$ & $14 \%$ \\
\hline $\begin{array}{c}\text { Reciprocity } \\
(35)\end{array}$ & 18 & 10 & $26 \%$ & $23 \%$ \\
\hline $\begin{array}{c}\text { Network } \\
\text { Remodel } \\
(43)\end{array}$ & 24 & 84 & $100 \%$ & $100 \%$ \\
\hline $\begin{array}{c}\text { Revaluation } \\
(18)\end{array}$ & 91 & $9 \%$ & $12 \%$ \\
\hline $\begin{array}{c}\text { Total \# and \% } \\
\text { of responses }\end{array}$ & 8 & 19 & & $20 \%$ \\
\hline
\end{tabular}


There are only minimal differences in the overall relationship-focused coping responses between both sets of study participants, yet the differences that do occur within the dimensions of adaptation and revaluation may be important in understanding how some of these women cope through relationships .

As previously noted, problem-focused coping is mentioned slightly more often among non-attendees than attendees and they spoke most often about education and self-determination. With this in mind, it follows that the strongest use in this coping category would be in the "revaluation of self" dimension as it implies monitoring and assessing one's contribution toward the relationship as important in their coping with illness:

"It's not just the normal things. It's get my education. It's get the best job I can. Get as much money in the bank [for her] before anything were to happen..." (Reese, non-attendee)

\author{
"The best way I can take care of my family is by taking care of \\ myself." (Ellen, non-attendee)
}

For the purposes of this project, however, the stories themselves are able to give more insight about relationship-focused coping among these women. Among the responses by the non-attendees, the primary themes were emphasizing sharing of responsibilities in their wellness/illness, faimess and quality of their contributions to their relationships. One woman told the story of how the illness brought her and her ex-husband back together as a means of helping her out and renewing their commitment for each other: 


\section{Communal:}

"Here's the deal: I know you can't stand to be in the same room with me, but you're going to need medical coverage. You won't be able to work.' He looked into it. He said, 'Let's get remarried...'" (Aimee, non-attendee)

For the most part, the relationships they spoke of were mainly due to their relationships with young children or grandchildren. There were also references to spouses as being supportive and parents who were concerned, which will be discussed further in the review of the support sources. Some attendees referred to the support group as a type of 'family'. However, these comments were not coded as relationship-focused since the definitions of these dimensions are targeted on relationships among family members. An argument could be made that family is only limited to the definition of the people involved and that the dimensions may also be applicable to other people in a woman's social network as well.

The attendees mentioned network remodeling which included negative or positive directions in the codes, as were all of the codes used in this study. It was anticipated to hear more attendees cope with their illness by networking with others who have lupus and this seems to be the case. Remodeling was also the dimension most used by the non-attendees, but not mentioned as often. The main remodeling that occurred was in changing social contacts and friends to improve a variety of adjustments ranging from physical to emotional areas. When mentioned by either set of study participants, this was the code most likely to elicit emotional responses, particularly when discussing family. This 
was true for the non-attendees as well, but mentioned on an average more among those who attended the self-help groups:

"I have friends I have just given up because they won't take the time to listen to me or get educated..." (Cindy, attendee)

"There were some people that I actually stopped associating with as much because they were- they drew too much of my energy. Do you know what I mean? So, I don't do as much with them as I used to simply because I don't have the energy for it." (Joanne, attendee)

What may be happening among the non-attendees is more of a close-in approach to facing the stress of illness. Perhaps the reliance on relationshipfocused is for the comfort of being with people they know and have investments in and not with 'strangers' or those outside their network. It may even be that the security of the roles within a family provide them the motivation to utilize this form of coping more so than the attendees. This category of coping is focused primarily on the relationships among family members and the results from this analysis suggest that a reason for non-attendees to choose not to participate in self-help groups may be due to their pre-occupation with monitoring closer relationships that directly affect them daily. The dimension of relationship adaptation which was mentioned more by non-attendees further reinforces this necessity for proximity as it relates to the assistance from the family unit with daily living requirements such as chores, responsibilities and general support:

"Almost every day I get my nap. He plays video games and I take my nap when the other one is napping." (Cheryl, non-attendee) 
If the assumption is that they choose not to participate in groups because they perceive support groups as a bunch of 'strangers' and lupus not being a strong enough reason to invest in the relationships, then understanding more about the types of support and the sources from which they draw from may assist in bridging this gap.

Building the support fund

The types of support were categorized into both emotional and instrumental forms. The emotional forms of support were forms that be used to focus on the emotional strategies in coping. For example, counseling or social activities were considered emotional forms due to the support they offered. The instrumental forms were targeted to address the elements of lupus such as symptoms, disability or education. An example of these would be medical attention, financial or literature.

The types of support sought by both the attendees and the non-attendees we reviewed and analyzed from the interviews and the results are outlined in the chart below (Table 9). The types of support are categorized into emotional (E) or instrumental forms (I) that were most commonly mentioned by all study participants. The table below presents the most common responses: 
Table 9

Types of Social Support

\begin{tabular}{|c|c|c|c|c|}
\hline $\begin{array}{c}\text { \# of Types of } \\
\text { Support Mentioned }\end{array}$ & $\begin{array}{l}\text { Attendees } \\
(\mathrm{N}=12)\end{array}$ & $\begin{array}{l}\text { Non- } \\
\text { Attendees } \\
(\mathrm{N}=7)\end{array}$ & $\begin{array}{c}\% \text { of } \\
\text { Attendee } \\
\text { Responses per } \\
\text { Type }\end{array}$ & $\begin{array}{c}\% \text { of } \\
\text { Non- } \\
\text { Attendee } \\
\text { Responses } \\
\text { per Type }\end{array}$ \\
\hline $\begin{array}{c}\text { Disease Management } \\
\text { (I) } \\
\text { (87) }\end{array}$ & 54 & 33 & $22 \%$ & $24 \%$ \\
\hline $\begin{array}{c}\text { Concern or } \\
\text { understanding }(E) \\
(131)\end{array}$ & 91 & 40 & $36 \%$ & $30 \%$ \\
\hline $\begin{array}{c}\text { Written or verbal } \\
\text { Information (I) } \\
(94)\end{array}$ & 60 & 34 & $24 \%$ & $25 \%$ \\
\hline $\begin{array}{l}\text { Living skills (E) } \\
\text { (31) }\end{array}$ & 22 & 9 & $9 \%$ & $7 \%$ \\
\hline $\begin{array}{l}\text { Physical Assistance(I) } \\
\text { (4) }\end{array}$ & 3 & 1 & $1 \%$ & $<1 \%$ \\
\hline $\begin{array}{c}\text { Social Activities (E) } \\
\text { (16) }\end{array}$ & 10 & 6 & $4 \%$ & $4 \%$ \\
\hline $\begin{array}{c}\text { Outreach source (I) } \\
\text { (21) }\end{array}$ & 9 & 12 & $4 \%$ & $10 \%$ \\
\hline $\begin{array}{c}\text { Total \# of responses } \\
(384)\end{array}$ & 249 & 135 & $100 \%$ & $100 \%$ \\
\hline
\end{tabular}

The women who attended the self-help groups were mentioned seeking emotional forms of support more than the non-participants. All the study participants mentioned seeking concern or understanding, disease management and information the most. Both the information and the disease management statements made by the attendees were encompassed primarily around the emotional relationship with their medical provider as a calming influence: 
"My naturopath has been a huge resource helping me deal with the side effects of different medicines and not having to freak out. The first time I woke up with muscle cramps in my legs so bad and not knowing what it was, and Chuck wants me to go to the emergency room and finding out that she just looks it up and, "Oh, this drug is (inaudible) magnesium," and having a simple vitamin. So that's been really huge."

(Rhonda, attendee)

Attendees did seek emotional-forms of support from their physicians, which may not be the most appropriate or viable source for this type of information. They were more likely to rely on the 'bedside manner' of their physicians than non-attendees and expressed more disappointment when they were unable to receive any treatment for their symptoms or to be 'heard' when they wanted to be included in the treatment planning.

The attendees also utilized more opportunities for emotional disclosure within social settings and expressed their perceptions of other people's 'willingness' to listen:

\footnotetext{
"“... since I've had Lupus, whenever I say - get up the courage to admit to somebody that are not too familiar with it, and I say, "I have Lupus," nine times out of ten, they say, "Well, my sister has Lupus, " or my aunt, or my mother..." (Donna, attendee)
}

It appeared throughout their interviews that they had a tendency towards perceiving the openness of people and took more opportunities (or seemed to make more effort) to express themselves to those around them. Sometimes these opportunities did result in negative experiences including rejection or disinterest from those others. The women who attended groups had a tendency to complain more about not being "heard": 
"I had already learned about educating people and how there's just no way you can talk to some people about it. They just put the wall up..." (Joanne, attendee)

"I guess what I need is for those close to me to understand when say, "I just really can't. No." (Cat, attendee)

The non-attendees seemed to seek out more instrumental forms of support such as information, disease management and outreach services such as organizations (but not support groups). The instrumental forms of support coincide with the problem-focused coping that they also seem to utilize more than the attendees. The discussions regarding their support choices were about taking active parts in their treatments and felt it important to be informed when they spoke with their providers:

"It's definitely manageable. All you need to do is educate yourself and follow doctor's orders. Basically, that's the advice I got from my doctor. It seems to be working." (Nancy, non-attendee)

They mentioned more positive experiences with their physicians and expressed their happiness with being active in the treatment decisions. In contrast to the attendees, these women relied less on their medical providers for emotional forms of support, even though they seemed to share the same amount of interest in disease management types of support. Interestingly enough, nonattendees also showed more types of outreach (primarily lupus and health organizations) and social activities. The social activities that they mention mostly have to do with the younger women and who have children. Some of the comments by both sets of participants have to do with social activities and also 
include some negative experiences such as not being able to plan or keep their social engagements:

"I want people to understand that if I say, 'Yeah, let's go to the movies on Tuesday,' and then I call you up Tuesday afternoon and say, 'It ain't going to happen.' I don't want you to think that I'm not going because I've decided I don't like you; because a movie isn't what I want to do; I've gotten a better offer; any of the above."

(Aimee, non-attendee)

The match between type and source is important in ensuring receiving support benefits and it follows that those women who were more inclined to choose particular strategies were going to participate in or seek a source of support to match what they were looking for. The results of this study so far have followed the expectations of attendees relying on emotion-focused strategies of support and seeking more emotional forms of support than the nonattendees. The crucial part of this study lies now in the determination of the sources for support. The results from this study show only that the study participant sets showed more mention of statements in these areas, but not at the exclusion of all the rest. As previous research suggests, there is a combined action among all coping processes, dimensions and types of support and this study reinforces that.

For the remainder of this analysis, the summation of the sources of support will explore the final set of differences between the women who attend self-help support groups and those women who do not. 
Considering the source

The sources of support for individuals facing lupus tend to be required to be flexible, forgiving and thorough. Due to the inconsistency of the symptoms, there is a great deal of variability in the timing, location and frequency which support will be sought. Many of the women interviewed expressed just as much frustration with their sources as they did with themselves for needing the resources as much as they did. A few of the women (5) from both the attendees and the non-attendees sets claimed to be "Type A" personalities, thus explaining the frustration they experience whenever they have to accept that they are unable to accomplish something on their own when they want to. The younger women with children mentioned it when they were referring it to having the energy with their children. The older women expressed it less, but the frustration is still present as it is compounded with the signs of aging.

The following table identifies the sources of support sought by both sets of study participant sets (Table 10): 
Table 10

Sources of Social Support

\begin{tabular}{|c|c|c|c|c|}
\hline $\begin{array}{l}\text { Sources of } \\
\text { Support } \\
\text { (\# of } \\
\text { responses) }\end{array}$ & $\begin{array}{l}\text { Attendees } \\
(\mathrm{N}=12)\end{array}$ & $\begin{array}{c}\text { Non-Attendees } \\
(\mathrm{N}=7)\end{array}$ & $\begin{array}{c}\% \text { of } \\
\text { Responses } \\
\text { Attendees }\end{array}$ & $\begin{array}{c}\% \text { of } \\
\text { Responses } \\
\text { Non- } \\
\text { Attendees }\end{array}$ \\
\hline $\begin{array}{l}\text { Family } \\
\text { Members } \\
(30)\end{array}$ & 21 & 9 & $8 \%$ & $6 \%$ \\
\hline $\begin{array}{l}\text { Medical } \\
\text { Providers } \\
\quad(99)\end{array}$ & 58 & 41 & $22 \%$ & $30 \%$ \\
\hline $\begin{array}{l}\text { Written } \\
\text { Materials } \\
\text { (24) }\end{array}$ & 13 & 11 & $5 \%$ & $8 \%$ \\
\hline $\begin{array}{l}\text { Internet } \\
\text { (39) }\end{array}$ & 22 & 17 & $8 \%$ & $12 \%$ \\
\hline $\begin{array}{l}\text { Social Network } \\
\text { (26) }\end{array}$ & 20 & 6 & $8 \%$ & $4 \%$ \\
\hline $\begin{array}{l}\text { Self-Reliant } \\
\text { (31) }\end{array}$ & 17 & 15 & $6 \%$ & $11 \%$ \\
\hline $\begin{array}{c}\text { Employment } \\
\text { (30) }\end{array}$ & 13 & 17 & $5 \%$ & $12 \%$ \\
\hline $\begin{array}{l}\text { Lupus } \\
\text { Organizations } \\
(118)\end{array}$ & 95 & 23 & $36 \%$ & $16 \%$ \\
\hline $\begin{array}{l}\text { Faith-based } \\
\text { Organizations } \\
(6)\end{array}$ & 4 & 2 & $2 \%$ & $1 \%$ \\
\hline $\begin{array}{l}\text { Total \# of } \\
\text { Sources } \\
\text { mentioned } \\
(404)\end{array}$ & 263 & 141 & $100 \%$ & $100 \%$ \\
\hline
\end{tabular}

The results from the analysis of the support sources showed that nonattendees sought out medical providers as their primary source of support and more so than the women who attended support groups. They also used slightly 
more written sources of information and apparently were more inclined to use the internet:

"...information I've gotten from the different websites, like the UK website has been an extreme help to me and an abundance of information. I have it saved as one of my favorites on my internet explorer. Those two things; and I'm constantly referring to them..." (Ellen, non-attendee)

There were a few participants (both attendees and non-attendees) who mentioned that they were discouraged by their medical providers in seeking or searching the internet and media for information about lupus. The concern was that there might be a chance that they will get inaccurate and possibly harmful information that might interfere with their adjustment. Although the concern was emotionally-based and that the physicians stated that they didn't want the them to become frightened with the misinformation, all study participants went against their doctors' orders simply because the had 'the need to know'.

Their social network and family member sources were not as utilized as the non-attendees, which makes a point of interest into what their networks are really about. Again, previous research has speculated that the reason for some people not to utilize support groups is due to their already existing networks providing them with enough support. Whether this is the case here or if it just might mean that they do not need their support network as much as others, remains to be studied. There were some non-attendees who mentioned interaction with their mothers as potentially negative sources of support that can occur within the family network: 
"Because parents feel responsible. My mom's first thing, 'No one in our family has Lupus. How the hell did you get that Lupus. Don't blame me for it." (Nancy,)

"My mother. I didn't really have a relationship with her until she found out I was sick, and that was like three years ago. And then she called and said, "You have to talk to me because you're sick and you're dying." (Reese)

It would appear that non-attendees do seek sources for emotional forms of support, but they just tend to be more selective in what sources they use. This leads into exploring the reasons why some non-participants do not wish to utilize support groups as a resource.

The employment source is also utilized as the statements by the nonattendees suggested that the ability to maintain working is a source of independence for them:

"I had a big job. I was the career girl and my job meant that I was in the office at seven in the morning and sometimes still there at like eight at night. It was a big job. Slowly but surely I found that I just couldn't do it. By stubbornness I was not recognizing what was going on. I kept saying, "I'm a little low on energy. I'll have another Snickers bar. Let me slam back another diet Coke." I was just doing everything and anything to try and pull enough energy together to get through the day." (Aimee, non-attendee)

This goes along with the category of "self-reliant", which was designed to determine themselves as a source. The non-attendees would appear to be task oriented, independent and goal-oriented in their overall adaptation to lupus.

For the women who attend groups, they showed more reliance on their family members and lupus groups for support sources. This would appear to follow along with the reliance on seeking understanding and good listeners. The 
sources they mention could actually provide them a variety of services including medical information, written materials, their social network and so forth. Earlier it was determined that there is a reliance on the medical sources for emotional, as well as medical information. These results do not confirm a rigid source network for either set of participants. It simply gives a glimpse of what these women mentioned during a brief and one-time discussion about their social support needs and hoe it relates to their choices for support.

It is clear that the lupus groups is a significant source of support for those women who attend them. The final analysis of this project is to determine what the reasons are behind the choices these two sets make (Table 11).

Table 11

Top Reasons for Not Attending Groups

\begin{tabular}{|c|c|}
\hline Attendees & Non-Attendees \\
\hline Don't want to be reminded of illness & Support is 'good enough' \\
\hline Don't want to hear whining & Fear/Keep it private \\
\hline No energy/tired & Not as sick/Don't need it \\
\hline Too ill & Night/Time not convenient \\
\hline $\begin{array}{c}\text { Does not provide enough emotional } \\
\text { support }\end{array}$ & Family time \\
\hline
\end{tabular}

Both attendees and non-attendees were included in this analysis because the actual attendance patterns for those women who identified themselves as attendees showed minimal attendance once the analysis of support group materials were received. In addition to the participant observations made at the 
support group meetings at the three group sites, materials such as flyers, attendance and speaker information group sites, materials such as flyers, attendance and speaker information were evaluated. The attendance patterns for those women who attended were more frequent during speakers or after a long absence. At the meetings, the names of those that hadn't attended in awhile were mentioned due to concerns of their well-being or having moved away from the area. Although concern was raised, it is uncertain if there was any follow up from the Portland group on the whereabouts or health status of the individuals in question. The Newberg group was very small and a call was usually made at some point to check. The Coast group are more actively involved with each other both in and out of the group, at least more than the other two, and news would usually make it back to the group about the person they were concerned about.

The fluctuations in attendance patterns for those women who were attendees were similar to those reasons given by the non-attendees. Interestingly enough, the attendees were the ones who mentioned the distaste for whining or being reminded of their illnesses more than the non-attendees. When asked about their initial perspectives or opinions about support groups, non-attendees were very positive. The decisions to not attend were not based on anger or negative experiences, nor were they necessarily opposed to groups since a few of them had belonged to other types of groups in the past. It seems that the decisions were more about what they felt they needed. The attendees spoke a 
great deal about what they received from attending the groups, but they spoke very little about what they were offering. Some offered information about medications or doctors, but for the most part, the primarily attended for the emotional support they felt they received.

In the analysis, the non-attendees appear to invest into the relationships in their lives, but very frugally. They spend energy into managing their illness, yet seem to feel less control in their lives. Whether they rely as much on emotional support or just don't feel that these groups offer the right support is not clear from this brief study. Even though non-attendees viewed support groups and on-line sources differently, it is clear that communication in some form or another is a supportive strategy and resource that is utilized to some degree. The format or structures of the groups, therefore, may very well be something that could be designed to be more attractive, useful and, therefore, more effective in assisting these women who apparently prefer to 'go it alone':

"Not in that environment. I would rather deal with it myself." (Reese, non-attendee)

Both sets of study participants put a large amount of trust, respect and control to their attending medical providers, either for medical partnership in managing their health or for the emotional support to be assured that things will be alright. With this influential role, the medical community is in the position.

The generalization regarding support groups is that they are a therapeutic source of support. The reasons mentioned for their decisions in attending 
groups did focus on receiving emotional-forms of support in the forms of emotional support such as talking and to develop relationships with members. They did, however, mention the importance of seeking the instrumental forms of support such as information regarding disease management. Their attendance patterns did vary with more often than not having the illness be the primary reason why they are unable to attend. The similar reasons for participation as mentioned in Sandstrom's article were also mentioned, as anticipated.

Comparing the support groups

The self-help groups in this study meet monthly as mentioned at the beginning of this study with Newberg being the only one flexible to meet the needs of the facilitator's health restrictions. The group formats and apparent goals work for those individuals who only seek an occasional meeting to attend where they may get a little information and emotional release by being there. However, as these groups are structured now, it is believed that attendance to these meetings will not increase.

The four groups were very similar in the locations where meetings were held, the formats and agendas of the meetings, the variances in membership attendance, the status of illnesses among the members (diagnosed or not), and the types of support expectations that the members had (primarily emotionfocused. There were some differences in the level of intimacy between the larger metropolitan group and the other 'small-town' groups. In this study, 
Salem was considered somewhere in the middle between Portland and the other rural groups due to the population size being large, but the town is spread out and lacks a sense of cohesion spatially. For the purpose of this discussion, therefore, Salem is considered a metro location.

The metro groups had no personal connection or system set up to coordinate social activities amongst the group members. In fact, the two smaller towns, due to their size, did show there to be more opportunities for members to see each other within their communities, whereas the metro self-help groups were situated in cities that are larger leading to little chance of seeing anyone from the group in the grocery store, bank or other public areas (which the Coastal group took personal pride in being able to do). The groups were all minimally structured in their formats no matter what location and the atmosphere of the smaller town groups seemed more personalized discussion and participation. This did not seem to be present at the bigger support groups where members only see each other approximately three times a year. 


\section{Conclusion}

This study provided a starting point in exploring the complexities of lupus, women's experiences and the illness adjustment process as it pertains to participation in self-help support groups. These conversations provided building blocks for future study to learning more about the variability of experiences in facing the challenges brought on by lupus. They experience changes in health, in daily living capabilities, in their social and familial relationships including the ties to their communities. The resources they have available to them and the networks they establish to access them, working in conjunction with their personal coping strategies, are key components in managing their lives.

The primary research question in this study examined the reasons behind decisions some women make to either participate in a lupus self-help group or not. The premises underlying the study were to explore some components of their decision process in participation in self-help support groups believed to factor into the women's decisions including their coping strategies, the types and sources of social support, and their prior experiences involving their diagnosis, family histories and prior knowledge of lupus in general.

Previous research investigating the coping strategies involved in adjusting to illness point to coping as a dynamic and multi-dimensional process. When the strategies used by women at the time of their diagnosis were reviewed, the non-attendees clearly showed more reliance on the problemfocused strategies and supported some suggestions that immediate concerns 
towards targeting the stressor (lupus), rather than deal with their emotionfocused needs, may be something a group approach would not provide them. Interestingly, this group of women did not respond with any relationshipfocused methods, as they recalled their experiences when they diagnosed. The work by Charmaz (1983) and Thoits (1995) in buffering stress with strategies and social support indicate that, at the time of a stressor, control and self-esteem are central concerns. For some women, the use of problem-focused strategies to address the lupus directly by relying on, for example, information and medication that they are able to obtain and manage themselves, may be a more effective means of 'buffering' their immediate stress. It would seem that the recommendation of group attendance for these particular women would not provide the individual-'focused' perspective towards their own ability to manage or control the new changes.

Looking at strategies further, the differences between the groups lessened, showing that there seems to be a little bit of all approaches used by both sets of study participants. Additionally, the use of relationship-focused strategies among women who did not attend increased as they shared their experiences throughout their interviews, thus supporting the work by Folkman \& Lazarus (1980) and others in the suggestion that there is more variability in coping than consistency. What strategies are used at the beginning of the adjustment process evolve into different strategies at another time. The results from this study also suggests, that it is vital to explore the actual way people 
respond to a specific stressor, including timing, rather than just assess their needs generally. The incorporation of the relationship-focused coping dimensions provides a valuable category to coping research that has been overlooked in lupus studies and this work indicates there are some potential insights to be discovered.

The types and sources of support showed similar results to Sandstrom (1996) among men diagnosed with HIV/AIDS. The types of support sought by those women who attended self-help support groups were matched between their particular coping style. Overall, women who attended a self-help support group who showed a reliance on emotion-focused coping strategies also showed a tendency to seek emotional types of support such as group attendance, concern and understanding. The results from this study regarding the types and sources of support reinforce the study by Smith, et. al,,(1994) in that the timing and match of the social support in very important to a woman's adjustment needs. The results from this project also reinforces the study results by Dunkel-Schetter (1984) on how significant the role of and the support available from the medical provider plays in a woman's adjustment to illness, especially those seeking emotional forms and relying on emotion-focused strategies.

Finally, this study addressed the variances and specifics of lupus and how it applies to individuals in their support seeking choices. As mentioned, receiving a diagnosis of lupus is sometimes difficult due to the inconsistencies and lack of specific tests available. One woman interviewed became 
discouraged in seeking support resources simply because she has been unable to receive a diagnosis. This support is primarily being sought from a physician and the choice she has made is to stop going to the medical providers due to the frustration and emotional pain the diagnostic process is causing her. As a nonattendee, the primary resource is her medical provider and, as Rook (1984) points out, provision of instrumental forms of support is particularly beneficial for a person during acute times of stress, such as a diagnosis.

In the longitudinal study by McCracken, et al., (1995), the support seeking behaviors my be impaired if the patients are not provided both appropriate type or level of support sought from the medical providers that could very well effect their future support seeking behavior.

Finally, the decisions to attend or not attend self-help support groups simulate other support group research, specifically Sandstrom's study. The negative experiences or potential for experiencing more stress through group participation was mentioned interestingly enough from the attendees as they mentioned the reasons the reasons they do not attend a meeting. Specifically, they mentioned seeing others who are sick and feeling depressed due to others whining. This study supports the research by Galinsky \& Schloper (1977) and Helgeson \& Gottlieb (2000) in that successful support groups, and this study incorporates the self-help groups as well, are designed to reflect the individual differences and needs of those who attend in order to ensure benefits in coping and illness adjustment. 
This study indicated that whether these women identified themselves as attendees or not, the group attendance records and the statements from the women themselves show that these are not support groups in the long-term therapeutic sense. In fact, even the attendees use the same reasons as nonattendees to explain or justify their absences. The groups involved in the study reflect more of a drop-in format where the women need to check in for information or just need to be able to talk to those who they believe would understand what they are going through.

The number of women in this study that attend groups is not a direct reflection of the benefits these groups provide or the predominance for women to use more emotion-focused strategies. The membership lists for these groups show hundreds of names, yet the meeting average anywhere from five to fifteen women in attendance, depending on the agenda for the meeting. When there are speakers, attendance is higher. There are a number of women who have taken the initiative to sign up for membership, which, for the metropolitan group, is linked to registering for a national organization for lupus awareness and research. Those who sign up for the organization are not necessarily interested in participation in the support groups. In fact, signing up for information linked to the organization is yet another indication that instrumental forms of support are sought as a means of illness adaptation.

Similar sources and types of support are utilized by both attendees and non-attendees with differences only showing in the degrees and sources for 
emotional forms of support. The diagnostic experience, which can be very emotionally charged, would be an appropriate time to make an initial assessment of the individual needs. This type of assessment would provide some key information that would then lead to a more accurate and respectful understanding of their objectives in coping with their illness. From here, the medical provider would be less likely to give a blanket recommendation for support groups or instill in them a sense of fear in the patient to not seek information from other sources that may be inaccurate or frightening. The recommendations made will be tailored to the patient, thus leading to a sense of involvement for the patient in their treatment and that their needs were being "heard".

The limitations of this study included the following:

- Recruitment - the source of study participants was drawn solely from membership rosters; did not include medical providers and services

- Sample - small size; more locations; incorporate cultural communities

- Level of analysis - longitudinal study and more interviews

- Experience in methodology - use Grounded Theory to develop theory

- Time frame - too much time elapsed in some participants diagnosis date to analyze diagnosis impact

The strengths of the study are:

- Application of qualitative methodologies to encompass experiences

- Sample diversity - included non-attendees, appropriate age ranges, minority and four group locations

- Community interest - health care management, availability and decrease medical expenses

- Personal experience and current lupus diagnosis 
There are some recommendations that can be made at this level including an assessment tool to be developed and administered at the time of diagnosis. There can be improved communication and coordinated efforts within the medical community to explore and involve these women in their treatments and support resource developments as a tool for self-managed care that is being stressed at all levels of our healthcare system from service providers to health insurance companies as an effort to streamline costs.

Even though autoimmune disorders are incurable at this time, the management of the disease progression is possible. Learning to live effectively with lupus could buy time for someone until a cure or prevention resource is made available. Self-help support groups could be a valuable resource for many women, if attention to the specific needs and experiences of those with lupus is acknowledged. Steps toward gaining understanding begins through continued research efforts. 


\section{References}

Aikens, J.E., J.S. Fischer, M. Namey \& R.A. Rudick. (1997). A Replicated Prospective Investigation of Life Stress, Coping and Depressive Symptoms in Multiple Sclerosis. Journal of Behavioral Medicine, 20: 433-445.

Aldwin, C.M. and T.A. Revenson. (1987). Does Coping Help? A Re-examination of the Relation Between Coping and Mental Health. Journal of Personality and Social Psychology, 53,2: 337-348.

Berkman, Lisa F. (2000). Social Support, Social Networks, Social Cohesion and Health. Social Work in Health Care, 31,2: 3-14.

Burg, Matthew M. and Teresa E. Seeman. (1994). Families and Health: The Negative Side of Social Ties. Annals of Behovioral Medicine, 16: 109-115.

Charmaz, Kathy. (1983). Loss of Self: A Fundamental Form of Suffering in the Chronically Ill. Sociology of Health and Illness, 5,2.

Charmaz, Kathy. (1990). Discovering Chronic Illness: Using Grounded Theory. Social Science and Medicine, 30, 11: 1161-1172.

Cohen, S. and T.A. Willis. (1985). Stress, Social Support and the Buffering Hypothesis. Psychological Bulletin, 98: 310-357.

Creswell, John W. (1998). Qualitative Inquiry and Research Design: Choosing Among Five Traditions. Thousand Oaks: Sage Publications.

Dunkel-Schetter, Christine. (1984). Social Support and Cancer: Findings Based on Patient Interviews and Their Implications. Journal of Social Issues, 40,4: 77-98.

Folkman, Susan and Richard S. Lazarus. (1980). An Analysis of Coping in a Middle-aged Community Sample. Journal of Health and Social Behavior, 23 (September): 219-239.

Galinsky, Maeda J. \& Janice H. Schopler. (1977). Warning: Groups May Be Dangerous. Social Work, March: 89-93.

Gignac, Monique A.M. ((2000). An Evaluation of a Psychotherapeutic Group Intervention for Persons Having Difficulty Coping with Musculoskeletal Disorders. Social Work in Health Care, 32,1: 57-75.

Gilligan, C. (1982). In a Different Voice: Psychological Theory and Women's Development. Cambridge, MA: Harvard University Press.

Glasgow, Russell E., Lisa A. Stryker, Deborah J. Toobert and Elizabeth Eakin. (2000). A Socio-Ecologic Approach to Assessing Support for Disease SelfManagement: The Chronic Illness Resources Survey. Journal of Behavioral Medicine, 23,6: 559-583.

Gore, Susan. (1985). Social Support and Styles of Coping with Stress. In S. Cohen and S.L. Syme (Eds.), Social Support and Health (pp. 263-278). New York: AcademicPress.

Hafen, Brent Q., Kathryn J. Fransden, Keith J. Karren and Keith R. Hooker. (1992). The Health Effects of Attitudes, Emotions, Relationships. Utah: EMS Associates.

Helgeson, Vicki S. and Benjamin H. Gottlieb. (2000). Support Groups. In S. Cohen, L. Underwood and B. Gottlieb (Eds.), Social Support Measurement and Intervention: A Guide for Health and Social Scientists, (pp.221-245). New York: Oxford University Press. 
Kelley, Jane E. and Mark A. Lumley. (1997). Health Effect of Emotional Disclosure in Rheumatoid Arthritis Patients. Health Psychology, 16,4: 331-340.

Komproe, Ivan H., Mieke Rilken, Wynand J.G. Ros, Jacques A.M. Winnubst, and Harm t' Hart. (1997). Available Support and Received Support: Different Effects Under Stressful Circumstances. Journal of Social and Personal Relationships, 15: 579-605.

Lazarus, Richard S. (2000). Toward Better Research on Stress and Coping. American Psychologist,55,6: 665-673.

Littrell, Jill. (1996). How Psychological States Affect the Immune System: Implications for Interventions in the Context of HIV. Health \& Social Work, 21: 287-295.

Lupus Foundation of America website: www.lupus.org

Lupus Foundation of America: Texas Gulf Coast Chapter. http://www.lupustxgcc.org

McCracken, Lance M., Elizabeth M. Semenchuk, and Virginia L. Goetsch. (1995). Cross-sectional and Longitudinal Analysis of Coping Responses and Health Status in Persons with Systemic Lupus Erythematosus

Mohr, David C., Leah P. Dick, David Russo, Jodi Pinn, Arne C. Boudewyn, William Likosky and Donald E. Goodkin. (1999). The Psychological Impact of Multiple Sclerosis: Exploring the Patient's Perspective. Health Psychology, 18,4: 376-382.

Newman, Stanton. (1990). Coping with Chronic Illness, In P. Bennett, J. Weinman \& P. Spurgeon (Eds.), Current Developments in Health Psychology (pp. 159-175). New York: Harwood Academic Publishers.

Pakenham, Kenneth I. (1999). Adjustment to Multiple Sclerosis: Application of a Stress and Coping Model. Health Psychology, 18,4: 383-392.

Revenson, T.A. and B.J. Felton. (1989). Disability and Coping as Predictors of Psychological Adjustment to Rheumatoid Arthritis. Journal of Consulting and Clinical Psychology, 57: 344-348.

Reitschlin, John. (1998). Voluntary Association Membership and Psychological Distress. Journal of Health and Social Behavior, 39: 348-355.

Rook, Karen S. (1984). The Negative Side of Social Interaction: Impact of Psychological Well-Being. Journal of Personality and Social Psychology, 46: $1097-1108$.

Ross, Catherine E. and John Mirowsky. (1989). Explaining the Social Patterns of Depression: Control and Problem-Solving- or Support and Talking? Journal of Health and Social Behovior, 30: 206-219.

Sandstrom, Kent L. (1996). Searching for Information, Understanding and SelfValue: The Utilization of Peer Support Groups by Gay Men with HIV/AIDS. Social Work in Health Care, 23: 51-75.

Sarason, Barbara R., Edward N. Shearin, Gregory R. Pierce and Irwin G. Sarason. (1987). Interrelations of Social Support Measures: Theoretical and Practical Implications. Journal of Personality and Social Psychology, 52,4: 813-832.

Schwartz, Carolyn E. (1999). Teaching Coping Skills Enhances Quality of Life More Than Peer Support: Results of a Randomized Trial with Multiple Sclerosis Patients. Health Psychology, 18,3: 211-220. 
Schwartz,Carolyn E. and Rabbi Meir Sendor. (1999). Helping Others helps oneself:

Response Shift Effects in Peer Support. Social Science and Medicine,

48: 1563-1575.

Smith, Carol E., Karen Fernengel, Carolyn Holcroft, Ken Gerald and Lydia Marien. (1994). Meta-Analysis of the Associations Between Social Support and Health Outcomes. Annals of Behavioral Medicine, 16, 4: 352-362.

Strauss, Anselm and Juliet Corbin. (1998). Basics of Qualitative Research: Techniques and Procedures: for Developing Grounded Theory. Thousand Oaks: Sage Publications.

Thoits, Peggy A. (1982). Conceptual, Methodological and Theoretical Problems in Studying Social Support as a Buffer Against Life Stress. Journal of Health and Social Behavior, 23: 145-159.

Tucker, Joan S.,Darlene K. Winkelman, Jeffrey N. Katz and Bonnie L. Bermas. (1999). Ambivalence Over Emotional Expression and Psychological WellBeing Among Rheumatoid Arthritis Patients and Their Spouses. Journal of Applied Social Psychology, 29,2: 271-290.

Wallace, Daniel J. (2000). The Lupus Book: A Guide for Patients and their Families. New York: Oxford University Press. 
APPENDIX A

INTERVIEW GUIDE 


\section{Interview Guide}

I. Preliminary Questions

A. Demographic data

1. What is your age?

2. What ethnicity do you identify yourself with?

3. Are you currently married or have a significant other? How long have you been together?

4. What can you tell me about your educational background?

5. Are you currently employed?

B. Discovery and current health

1. What, if anything, did you know about lupus before your diagnosis?

2. How long would you say you have known you had lupus? (Probes: diagnosed right away, mistaken diagnosis)

3. Do you have family members who have autoimmune disorders such as lupus?

4. Did you know individuals in your community with lupus or other autoimmune disorders before you were diagnosed?

5. Have you experienced any remissions in your symptoms? (Probes: frequency)

6. Are you currently facing other diseases that are lupus-related? (Probes: Sjögren's syndrome, Raynaud's phenomenon etc.)

\section{Diagnosis}

C. Impact of diagnosis: Thinking back to the time of your diagnosis...

Approximate Date of diagnosis:

1. Would you be able to describe for me your diagnosis experience?

2. What suggestions, at the time of your diagnosis, did the medical provider give you to assist in your coping with lupus? (Probes: diet, groups, relaxation techniques)

3. What were your primary concerns regarding your illness?

4. Who did you tell of your lupus diagnosis? (Probes: when, how)

5. What can you tell me of the reactions from your family, friends and/or coworkers when you told them of your diagnosis?

Since the time of your diagnosis, I would like to ask you some questions about how you cope...

D. Social Support

1. How do you feel about your current level of support you receive for your lupus?

2. What do you need from your support network to help you cope with lupus?

3. Where do you feel you get the most useful support to help you cope with lupus? (Probe: In what ways?)

4. Are there people you feel uncomfortable in talking to about your illness? If so, who are they and why?

5. Do people at work know of your illness? Do they provide you means of support? (Probes: flexible schedule, work station modifications, medical coverage resources, time off)

6. Has your diagnosis affected your relationships with others? (Probes: changes in frequency or "closeness" of contact with others, problems or 
tensions in interactions, withdrawal or fear of sharing, changes in feelings about others)

\section{Involvement in Support Systems \\ General Questions: \\ 1. How did you find out about the support group? \\ 2. Who suggested participation in a support group to you? \\ 3. What were your reasons to participate or not to participate? (Probe: speaking in front of a group, prefer privacy) \\ 4. Have you participated in a lupus group before our discussion here?}

If so,...

\section{Group Participation}

1. What can you tell me about your experiences in participating in the group?

2. Do you know any of the members outside of the group socially?

3. Would you say you seek information or emotional support from the group experience?

4. Do you feel the group offers you enough of the type of support you seek?

5. Are there members of your community with lupus that you know do not participate in the group?

6. Have you attended the meetings regularly? Has your attendance varied? For what reasons? (Probes: illness-related problems, transportation. schedule conflict, topic of meeting not of interest)

7. Do you continue attending meetings during your remissions? (If applicable) If not, can you tell me why?

8. In what ways has participation affected you? Your relationships? Your adaptation to the illness? Your self-concept?

9. What other support resources have you sought in your adjustment to lupus?
a. internet resources
b. memberships to other lupus-related organizations (e.g. LFA)
c. memberships to organizations that are not lupus-related (e.g. gym, hobbies)
d. books, articles, printed media

If not,...

\section{No Group Participation}

1. What information or experience did you have with support groups prior to your diagnosis? (Probes: opinions of others, experiences of others)

2. How do you feel about groups for individuals with lupus? Support groups in general?

3. What methods of coping with the illness do you find most helpful for you? (Probes: sharing your experiences, information seeking only, social activities, relaxation techniques, non-health related activities)

4. Would you consider participation under different circumstances? (Probes: meeting schedules, places, assistance with transportation, number of members in meetings) 
5. If you were to attend a group, what would you look for or need from the experience? (Probe: facilitator, location, meeting times, activities, resources, members)

6. What other support resources have you sought in your adjustment to lupus?

a. internet resources

b. memberships to other lupus-related organizations (e.g. LFA)

c. memberships to organizations that are not lupus-related $(\mathrm{e}, \mathrm{g}$, gym, hobbies)

IV. Administration of Brief CIRS (See attached)

V. Closing of the Interview Process

1. What advice would you offer to someone, who has just been recently diagnosed with lupus, regarding support group participation? (Probe: Do you think it would be beneficial or not)

2. How has your view of yourself changed over time from diagnosis to present?

3. Would you like to share any additional information or comments before we conclude this interview?

4. (Pilot study only) Do you have any recommendations or suggestions about the interview questions?

Thank you for your participation in this study 
APPENDIX B

NORTHWEST HEALTH FOUNDATION

GRANT CONFIRMATION LETTER 


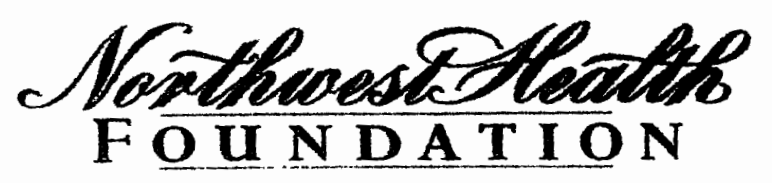

April 7, 2003

Nancy Chapman, PhD, Research Supervisor

College of Urban and Public Affairs, PSU

P.O. Box 751

Portland, Oregon 97215

Re: Grant Proposal No. 2003-315

Dear Dr. Chapman:

We have received your application to the Student Research Grant Program entitled Group Participation Among Women Diagnosed with Systemic Lapus Erythematosis. The Board and Staff of the Northwest Health Foundation are pleased to let you know that funding for this project has been approved in the amount of $\$ 2,980$ for direct costs only.

As Research Supervisor for Maria Pfeifer, you will remain our primary contact for this grant and all correspondence will be sent to you.

A check in the amount of $\$ 2,980$ is enclosed, along with two copies of a grant agreement. One copy of the agreement must be signed and retarned to the Northwest Health Foundation before grant funds are deposited.

At the end of the grant period, we request that a letter be sent to the Foundation reporting on activities that occurred during the research related to this funding. You will find a copy of the final report guidelines enclosed.

Please contact the Foundation if you have any questions regarding this grant or any of our other programs.

Sincerely,

Thomas D. Aschenbrener

President

Enclosure 